\title{
The Postsubiculum and Spatial Learning: The Role of Postsubicular Synaptic Activity and Synaptic Plasticity in Hippocampal Place Cell, Object, and Object-Location Memory
}

\author{
David Bett, ${ }^{1,2 \star}$ Cassie H. Stevenson, ${ }^{1 \star}$ Kate L. Shires, ${ }^{1}$ Michael T. Smith, ${ }^{1}$ Stephen J. Martin, ${ }^{1}$ Paul A. Dudchenko, ${ }^{1,2} \mathfrak{S}$ \\ and Emma R. Wood ${ }^{1}$ \\ ${ }^{1}$ Centre for Cognitive and Neural Systems, School of Biomedical Sciences, University of Edinburgh, Edinburgh EH8 9JZ, United Kingdom and ${ }^{2}$ Psychology \\ Division, School of Natural Sciences, University of Stirling, Stirling FK9 4LA, United Kingdom
}

Visual landmarks exert stimulus control over spatial behavior and the spatially tuned firing of place, head-direction, and grid cells in the rodent. However, the neural site of convergence for representations of landmarks and representations of space has yet to be identified. A potential site of plasticity underlying associations with landmarks is the postsubiculum. To test this, we blocked glutamatergic transmission in the rat postsubiculum with CNQX, or NMDA receptor-dependent plasticity with D-AP5. These infusions were sufficient to block evoked potentials from the lateral dorsal thalamus and long-term depression following tetanization of this input to the postsubiculum, respectively. In a second experiment, CNQX disrupted the stability of rat hippocampal place cell fields in a familiar environment. In a novel environment, blockade of plasticity with D-AP5 in the postsubiculum did not block the formation of a stable place field map following a $6 \mathrm{~h}$ delay. In a final behavioral experiment, postsubicular infusions of both compounds blocked object-location memory in the rat, but did not affect object recognition memory. These results suggest that the postsubiculum is necessary for the recognition of familiar environments, and that NMDA receptor-dependent plasticity in the postsubiculum is required for the formation of new object-place associations that support recognition memory. However, plasticity in the postsubiculum is not necessary for the formation of new spatial maps.

\section{Introduction}

A central feature of spatial cognition is that familiar landmarks, when available, guide spatial responses (Wolbers and Hegarty, 2010) (for review, see Dudchenko, 2010). On a radial maze, for example, shifting the extramaze landmarks by $180^{\circ}$ about the maze causes a corresponding shift in rat arm choices (Suzuki et al., 1980). Similarly, for hippocampal place cells, Muller and Kubie (1987) found that the place fields rotated by $90^{\circ}$ when a cue card on the wall of a cylindrical environment was rotated by $90^{\circ}$. [To our knowledge, the first demonstration that place fields can be controlled by visual landmarks was by O'Keefe and Conway (1978).] Subsequent studies have shown that the firing direction

Received Nov. 27, 2012; revised Feb. 8, 2013; accepted March 12, 2013.

Author contributions: D.B., C.H.S., K.L.S., S.J.M., P.A.D., and E.R.W. designed research; D.B., C.H.S., K.L.S., M.T.S., S.J.M., P.A.D., and E.R.W. performed research; D.B., C.H.S., K.L.S., M.T.S., S.J.M., P.A.D., and E.R.W. analyzed data; D.B., C.H.S., S.J.M., P.A.D., and E.R.W. wrote the paper.

This work was supported by UK Biotechnology and Biological Sciences Research Council Grant BB/D001714/1 (E.R.W., P.A.D.). We thank Ms. Jane Tulloch for her expert assistance with histology on this project and Dr. Steven Huang for his assistance with electrode implantation.

${ }^{*}$ D.B. and C.H.S. contributed equally to this work.

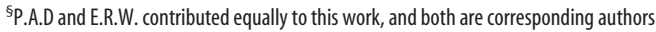

Correspondence should be addressed to Emma Wood or Paul Dudchenko at the above address. E-mail: emma.wood@ed.ac.uk or p.a.dudchenko@stir.ac.uk.

DOI:10.1523/JNEUROSCI.5476-12.2013

Copyright $\odot 2013$ the authors $\quad 0270-6474 / 13 / 336928-16 \$ 15.00 / 0$ of head direction cells, and the orientation of grid fields in grid cells, can be likewise controlled by a cue card in a cylindrical environment (Taube et al., 1990b; Taube, 1995; Hafting et al., 2005). Importantly, the anchoring of spatial firing to a landmark reflects a spatial association with the landmark, and not simply a sensory response (Goodridge et al., 1998).

Where in the brain are landmarks and spatial representations linked? A potential association site is the hippocampus, but removal of the hippocampus fails to abolish landmark learning in head direction cells (Golob and Taube, 1997, 1999). Landmark learning does, however, require NMDA receptor-dependent plasticity, as systemic administration of an NMDA receptor antagonist during exposure to a novel environment blocks the storage of newly formed place cell maps (Kentros et al., 1998; Rowland et al., 2011).

An alternative site for this plasticity is the postsubiculum (PoS; also referred to as the dorsal presubiculum; see Fig. 1). The $\mathrm{PoS}$ is considered an input structure to the hippocampal formation, as it projects to the entorhinal cortex (Witter and Amaral, 2004), and likely relays inputs from the retrosplenial cortex (Kononenko and Witter, 2012). The PoS contains head direction, grid, and border cells (Taube et al., 1990a; Boccara et al., 2010), and lesions of PoS cause the place fields of hippocampal place cells to shift unpredictably between sessions in a familiar environ- 


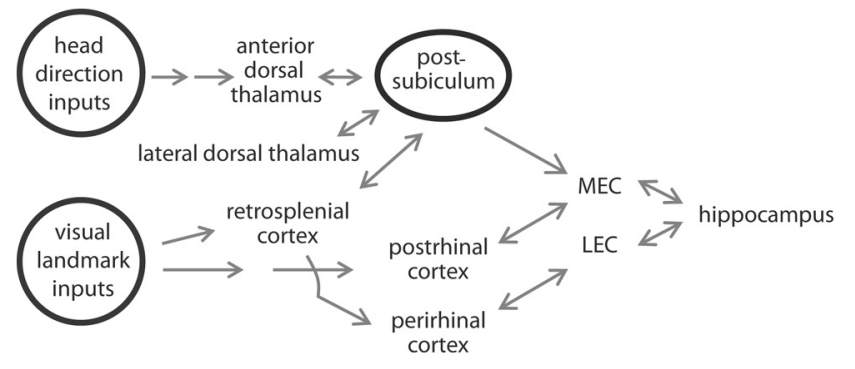

Figure 1. Potential circuit underlying landmark and directional associations. The current experiments test the hypothesis that the postsubiculum is a site of convergence for spatial (head direction) and visual landmark information. Alternative sites for the plasticity underlying the association between the internal representations of space and external landmarks, objects, or contexts include the retrosplenial, postrhinal, and perirhinal cortices. This circuit is based on the studies by Burwell et al. (1995) , Burwell (2000) , Deshmukh and Knierim (2011) , and Yoder et al. (2011) , and not all connections (e.g., the direct projection from visual cortical areas to P0S) are shown. MEC, Medial entorhinal cortex; LEC, lateral entorhinal cortex.

ment (Calton et al., 2003). Likewise, PoS lesions also substantially weaken the stimulus control of a cue card over the firing direction of head direction cells in the anterior thalamus (Goodridge and Taube, 1997). Combined lesions of the postsubiculum and parasubiculum weaken the spatial tuning of place cells (Liu et al., 2004). Damage to the postsubiculum or the postsubiculum and parasubiculum also impairs spatial navigation, spatial memory, and context conditioning (Taube et al., 1992; Kesner and Giles, 1998; Liu et al., 2001) (for review, see Yoder et al., 2011; Bett et al., 2012; Robinson and Bucci, 2012).

Though suggestive, these experiments leave open the possibility that the postsubiculum is simply a relay site for landmark information rather than being the site at which landmarks are associated with spatial representations. To test the hypothesis that the postsubiculum is the site of plasticity underlying landmark learning, we conducted neurophysiological and behavioral experiments in which we pharmacologically blocked AMPARmediated synaptic transmission or NMDAR-mediated plasticity in the postsubiculum. We found that blocking synaptic transmission in PoS disrupted place field stability in a familiar environment, and also impaired object-location memory. However, although blocking plasticity in the postsubiculum also impaired object-location memory, it did not disrupt the formation or storage of a new cognitive map.

\section{Materials and Methods}

\section{Overview}

The current study involved three experiments, each conducted in a separate group of rats. In Experiment 1, we established the efficacy of our drug infusions on postsubiculum function by assessing the effects of unilateral infusions of D-AP5 (an NMDA glutamate receptor antagonist), CNQX (an AMPA/kainate glutamate receptor antagonist), and artificial CSF (ACSF) on evoked potentials in postsubiculum and on the induction of long-term depression (LTD) in postsubiculum in terminally anesthetized rats. In Experiment 2, we compared the effects of these infusions on stability of place fields in a familiar environment, on the formation of new fields in a novel environment, and on the maintenance of these new fields after a 6 h delay. In Experiment 3, we tested the effects of D-AP5, CNQX, and ACSF infused just before exposure to novel objects in a familiar environment on subsequent memory ( $24 \mathrm{~h}$ later) for the objects (object recognition) and for the locations in which the objects had been placed (object location recognition).

\section{Experiment 1}

Animals

Male adult Lister Hooded rats (Charles River Laboratories), were used in this and the subsequent experiments. In Experiment 1, 29 rats, weighing
$250-500 \mathrm{~g}$ at the time of surgery, were housed in group cages (three or four per cage) with unrestricted access to food and water. In this and the following experiments, the rats were maintained on a $12 \mathrm{~h} \mathrm{light/dark}$ cycle, and all experiments took place during the light phase. All procedures in this and the following experiments were performed in compliance with national [Animals (Scientific Procedures) Act, 1986] and international [European Communities Council Directive of November 24, 1986 (86/609/EEC)] legislation on animal use.

\section{Compounds}

A $3 \mathrm{mM}$ solution of the AMPA/kainate receptor antagonist CNQX (disodium salt; Tocris Bioscience) and a $30 \mathrm{mM}$ solution of the NMDA receptor antagonist D-AP5 (Tocris Bioscience) were prepared by dissolving in ACSF [containing (in $\mathrm{mM}) 150 \mathrm{Na}^{+}, 3 \mathrm{~K}^{+}, 1.4 \mathrm{Ca}^{2+}, 0.8 \mathrm{Mg}^{2+}$, $155 \mathrm{Cl}^{-}, 0.2 \mathrm{H}_{2} \mathrm{PO}_{4}^{-}, 0.8 \mathrm{HPO}_{4}^{2-}$, in pyrogen-free water, $\mathrm{pH}$ 7.2]. Gentle sonication was required in the case of CNQX. The $\mathrm{pH}$ of the solutions was adjusted to 7.2 by the addition of concentrated phosphoric acid (CNQX) or $1 \mathrm{~mm} \mathrm{NaOH}$ (D-AP5), and drugs were stored in small aliquots at $-20^{\circ} \mathrm{C}$ before use.

\section{Postsubiculum cannulae surgery}

All surgery was performed using aseptic techniques. Before surgery, animals were anesthetized with isoflurane (Abbott Laboratories), placed on an isothermal heating pad, and positioned into a stereotaxic frame (Kopf). The skin was retracted to expose the skull. Small holes were made bilaterally into the skull (AP, $-7.5 \mathrm{~mm} ; \mathrm{ML}, \pm 5 \mathrm{~mm}$ ) for the implantation of stainless steel guide cannulae (26 gauge stainless steel; outer diameter, $0.46 \mathrm{~mm}$; Plastics One) into the PoS. Further burr holes were drilled at various positions, and small stainless-steel jeweler's screws (Fine Science Tools) were attached to the skull to provide anchor points for the dental cement. One guide cannula was implanted into each side of the brain using a stereotaxic arm angled $20^{\circ}$ from vertical, such that each cannula was advanced $3 \mathrm{~mm}$ from the surface of the brain (AP, $-7.5 \mathrm{~mm}$; ML, $\pm 5 \mathrm{~mm}$ ) in a ventromedial direction. Dental cement (Simplex Rapid Acrylic Denture Polymer; Kemdent) was then placed around the protruding section of the guide cannulae (taking care not to cover the ends) and over the screws to ensure that the guide cannulae maintained their position. A 33 gauge dummy injector was then inserted into each guide cannula. The dummy protruded $0.5 \mathrm{~mm}$ from the end of the guide cannula. The dummy injectors were the same depth and diameter as the injection cannulae used for the experimental drug infusions (see below, Recording procedures) and were used to prevent infection or blockage of the guide cannulae. Immediately following surgery, a subcutaneous injection of $0.08 \mathrm{ml} / \mathrm{kg}$ analgesic (Small Animal Rimadyl; Pfizer) in $2 \mathrm{ml}$ saline was administered to each rat. Analgesia (Large Animal Rimadyl; Pfizer) was available in the rats' water from $24 \mathrm{~h}$ before until $48 \mathrm{~h}$ after surgery.

\section{Recording procedures}

Approximately 1 week after being equipped with infusion cannulae, rats were anesthetized with urethane (ethyl carbamate; $1.5 \mathrm{~g} / \mathrm{kg} ; 0.3 \mathrm{mg} / \mathrm{ml}$, i.p.) and placed in a stereotaxic frame with the skull horizontal. Body temperature was monitored by a rectal probe and maintained at $36.2^{\circ} \mathrm{C}$ using an isothermal heating blanket. Depth of anesthesia was assessed throughout the experiment, and urethane top-ups of $0.2 \mathrm{ml}$ were administered as required. A concentric bipolar stimulating electrode (model SNE-100; Rhodes Medical Instruments; shaft diameter, $0.25 \mathrm{~mm}$; tip-toshaft separation, $0.5 \mathrm{~mm}$ ) was lowered into the laterodorsal nucleus $(\mathrm{LDN})$ of the thalamus (coordinates, AP, -2.9 ; ML, 2.4; DV, typically $4.0-4.5 \mathrm{~mm}$ below the dura), and a polytetrafluoroethylene-insulated monopolar platinum/iridium recording electrode (diameter, $0.103 \mathrm{~mm}$ ) was lowered into the postsubiculum (AP, $-7.5 \mathrm{~mm}$; ML, $2.8 \mathrm{~mm}$; DV, typically $2.5-3.0 \mathrm{~mm}$ below the dura) to record negative-going field EPSPs elicited by synaptic activity in the superficial layers of the postsubiculum in which afferents from the LDN terminate (van Groen and Wyss, 1992). (Postsubicular EPSPs were more reliably observed with stimulation of the LDN, as opposed to the anterior dorsal thalamic nucleus.) fEPSPs were amplified and sampled at $20 \mathrm{kHz}$ using a PC running custom-written LabView software developed by P. Spooner, University of Edinburgh, Edinburgh, UK. fEPSP amplitude and initial slope were 
monitored online; owing to the relatively small size of fEPSPs recorded and the resulting variability in slope, our analysis focused on fEPSP amplitude. Stimulation was delivered under computer control via a Neurolog system (NL800A; Digitimer). Appropriate electrode depths were determined based on characteristic changes in fEPSP sign and shape observed during implantation, and final depth adjustments maximized the amplitude of the negative-going fEPSP. Typical amplitudes ranged between -0.5 and $-1.0 \mathrm{mV}$, with a peak latency of $\sim 6 \mathrm{~ms}$; examples of fEPSPs are shown in Figure 3, $B$ and $D$.

After placement of the electrodes, a 30 min rest period was followed by the onset of baseline stimulation, consisting of biphasic constant-current pulses ( $0.2 \mathrm{~ms}$ in total duration; $0.5 \mathrm{~mA}$ ) delivered every $20 \mathrm{~s}$. After stable recordings had been obtained for at least $30 \mathrm{~min}$, an injection needle was inserted into the guide cannula ipsilateral to the electrodes. This was connected via plastic tubing to SGE syringes mounted in a syringe driver, and protruded $0.5 \mathrm{~mm}$ from the end of the guide cannula. To characterize the pharmacology of synaptic transmission in the LDN-postsubiculum projection, animals received an infusion (1 $\mu$ l over $20 \mathrm{~min}$ ), ipsilateral to the electrodes, of ACSF $(n=4), \operatorname{CNQX}(n=6)$, or D-AP5 $(n=5)$; recording continued for at least $90 \mathrm{~min}$ after the end of infusion. In a further experiment, infusions of $\operatorname{ACSF}(n=8)$ or D-AP5 $(n=7)$ were followed by an intermediate-frequency tetanus delivered to the LDN (two trains of 120 pulses at $60 \mathrm{~Hz}$; $60 \mathrm{~s}$ intertrain interval), delivered 15 min after the end of infusion; recording continued for a further 75 min after tetanization. In both experiments, fEPSP amplitude values were normalized to a $10 \mathrm{~min}$ baseline period immediately before the start of infusion, and group means were calculated.

\section{Histology}

At the end of each recording session, marking lesions were made by the delivery of biphasic $1 \mathrm{~mA}$ constant-current pulses (1 s per phase) to both stimulating and recording electrodes. Rats were killed by cervical dislocation, and brains were removed and stored in $4 \%$ formaldehyde overnight before embedding in egg yolk and further formalin fixation. Brains were sliced directly onto gelatin-coated slides using a cryostat. Slices of $30 \mu \mathrm{m}$ thickness were taken through the regions of interest and stained with cresyl violet. Correct placement of stimulating and recording electrodes and infusion cannulae was confirmed by examination under a light microscope.

\section{Experiment 2}

Animals

For Experiment 2, five rats, weighing 350-400 $\mathrm{g}$ at the time of surgery, were housed in individual cages. Before surgery and during recovery, all rats had unrestricted access to food and water. Two weeks after recovery from surgery, rats continued having unrestricted access to water, but were food restricted to $\sim 85-90 \%$ of their ad libitum body weight.

\section{Tetrodes and microdrives}

The recording microdrives were a modified version of Kubie's (1984) tripod design. Each microdrive had 16 HML-coated, $17 \mu \mathrm{m}$ (90\% platinum; 10\% iridium) wires (California Fine Wire), configured as four tetrodes. The tetrodes were threaded through a short length of 27 gauge thin-walled stainless-steel cannula (Small Parts). One end of each tetrode was flamed to remove a portion of the insulation, and individual wires from each tetrode were wrapped around separate pins of a MillMax plug and affixed with conductive paint (Electrolube; RS Components). A 22 $\mathrm{mm}$ length of thin insulated wire (Vishay) was soldered onto a spare pin on the MillMax plug to function as a ground wire. The plug was affixed to three screws with dental cement (simplex Rapid Acrylic Denture Polymer, Kemdent). The tetrodes, which were left protruding from the thin walled cannula, were then cut to $\sim 2 \mathrm{~mm}$ from the end of the feet, and an "outer" cannula (18 gauge Hypo Tube; Small Parts) was carefully placed over the 27 gauge cannula and was held in place using Vaseline. On the day of surgery, the tip of each wire was gold plated to an impedance in the range of $200-300 \mathrm{k} \Omega$.

\section{Surgical procedures}

During the surgery to implant the infusion cannulae (done as in Experiment 1), animals in Experiment 2 were also equipped with a recording microdrive, as detailed above. After placement of the cannulae in the postsubiculum, a small hole was drilled through the skull over the left hippocampus (AP, $3.5 \mathrm{~mm}$; ML, $2.4 \mathrm{~mm}$ ) for the tetrode array. The dura over the hole was punctured using a narrow gauge needle, and the tetrode drive was positioned and the protruding tips of the tetrodes were lowered into the brain (1.7 $\mathrm{mm}$ from brain surface), aimed just above the CA1 area. The outer cannula of the array was then lowered onto the skull to protect the exposed tetrodes. The ground wire on the drive was wrapped around a skull screw, and the connection was covered in silver paint. When this had dried, the drive was cemented in place, again using the skull screws as anchors. Cement was used to build "walls" around the exposed skull area so that the rat could not damage the drive after surgery. Once the cement had fixed, the screws on the drive were turned by $1 / 4$ to lower the tetrodes by $40 \mu \mathrm{m}$.

Immediately following surgery, a subcutaneous injection of $0.08 \mathrm{ml} / \mathrm{kg}$ analgesic (Small Animal Rimadyl; Pfizer) in $2 \mathrm{ml}$ saline was administered to each rat. Analgesia (Large Animal Rimadyl; Pfizer) was available in the rats' water from $24 \mathrm{~h}$ before until $48 \mathrm{~h}$ after surgery. All rats were given $10 \mathrm{~d}$ recovery from surgery and had exceeded their presurgery weights before progressing to the next stage of the experiment.

\section{Apparatus}

Single units were recorded using an Axona 32-channel system (Axona). The recording microdrive on the rat's head was connected to a headstage containing unitary gain operational amplifier chips for every screening or recording session. The signals were relayed via a flexible tethered cable to a ceiling-mounted commutator (Dragonfly Research and Development), and then to a preamplifier (Axona), which amplified the signal 1000 times. The amplified signals were relayed to the main recording system (Axona), bandpass filtered between 600 and $6000 \mathrm{~Hz}$, digitized at $50 \mathrm{kHz}$, and further amplified 10-40 times (DacqUSB software). During recording, $1 \mathrm{~ms}$ samples of signals that exceeded a preset amplitude threshold ( $0.2 \mathrm{~ms}$ before and $0.8 \mathrm{~ms}$ after the threshold was reached) were recorded and time stamped. The position of the rat was recorded by an overhead video camera, which was used to record (at a $50 \mathrm{~Hz}$ sampling rate) infrared signals emitted by light-emitting diodes attached to the rat's headstage. These LED positions were also time stamped by the DacqUSB software during recording.

Upon identification of one or more place cells (see below, Screening), cells were recorded as animals explored different cylindrical environments. Six distinctive cylindrical recording environments were used, varying in size, color, and texture as follows: Cylinder A, dark gray plastic walls and floor, $82 \mathrm{~cm}$ wide by $50 \mathrm{~cm}$ tall; Cylinder B, light gray plastic walls and floor, $62 \times 45 \mathrm{~cm}$; Cylinder C, terracotta plastic walls and floor, $62 \times 45 \mathrm{~cm}$; Cylinder D, black wooden floor and bendy fiber board walls, $77 \times 59 \mathrm{~cm}$; Cylinder E, black wooden floor and light gray cardboard walls, $75 \times 38 \mathrm{~cm}$; Cylinder F, gray wooden floor and gray cardboard walls, $59 \times 59 \mathrm{~cm}$. Attached to the inside wall of each cylinder was a distinctive cue card, and across cylinders these varied in color, size, and visual pattern. Each rat was assigned one cylinder as its familiar environment, and the remaining five cylinders were used as novel environments. During testing, a given cylinder was placed in the center of a circular enclosure $2 \mathrm{~m}$ in diameter, made from overlapping black curtains. A white sheet provided a false ceiling to this enclosure, and approximately centered within this ceiling were a camera, a light, and the recording commutator.

\section{Screening}

After a recovery period of at least $10 \mathrm{~d}$ following surgery, and before exposure to the cylindrical test environments, rats were plugged in to the recording system up to twice daily to screen for cells. During screening, rats were put on a circular table top in the recording room, but outside the curtained enclosure, and left to forage for small pellets (Dustless Precision Pellets, Bioserve). If suspected place cell activity was evident, single unit and position data was acquired during a 10 min pellet-chasing session on the circular table top for off-line analysis (see below, Data analysis). If place cell activity was confirmed, and was also observed the following day, rats would begin the behavioral testing procedures described below. If not, the electrodes were advanced by $\sim 20$ to $40 \mu \mathrm{m}$ by 
A

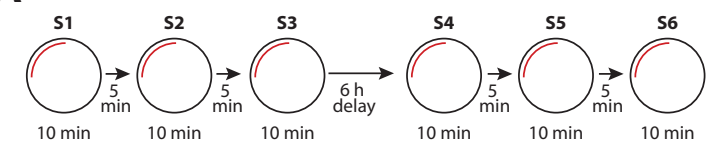

B

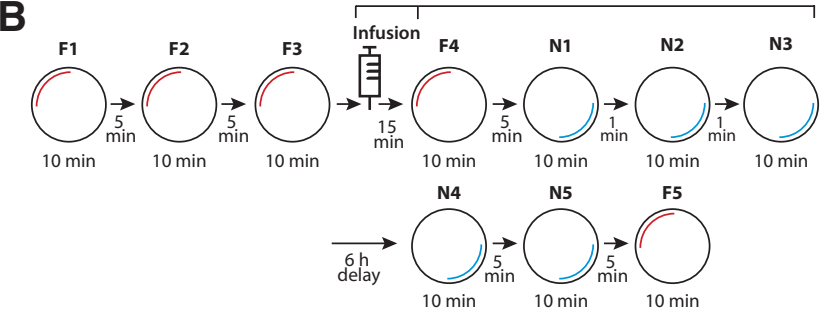

C

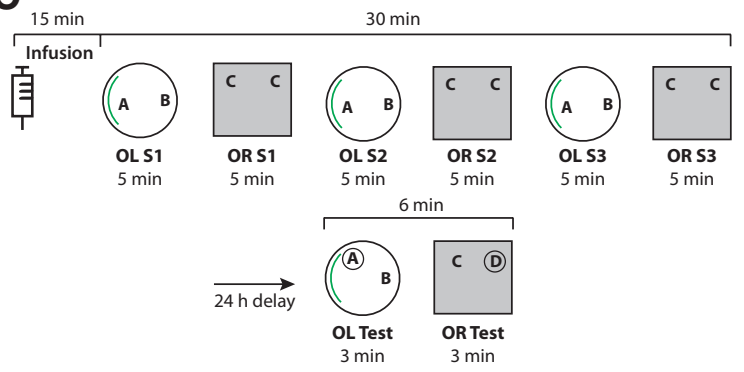

Figure 2. $\boldsymbol{A}-\boldsymbol{C}$, Procedures for Experiments $2(\boldsymbol{A}, \boldsymbol{B})$ and $3(\boldsymbol{C})$. $\boldsymbol{A}, 0$ n Day 1 , place cells were recorded during six sessions $(S 1-S 6)$ in the same environment. $\boldsymbol{B}, 0$ test days, the rats received three sessions (F1-F3) in this now familiar environment and then an infusion of ACSF, CNQX, or AP-5 into the postsubiculum. They were then replaced in the familiar cylinder (F4), and then given three sessions in a novel cylinder (N1-N3). After a $6 \mathrm{~h}$ delay, memory for the novel cylinder was tested by placing the animals back in the novel environment (N4, N5) and recording their place fields. Finally, a last session was conducted in the familiar environment (F5). C, In Experiment 3 , rats were tested with the same infusions and given repeated exposures to two different objects ( $A$ and $B$ ) in a cylinder equipped with a cue card, and two identical objects ( $C$ and $C$ ) in a square. Following a $24 \mathrm{~h}$ delay, rats were tested for their memory of the position of the objects in the cylinder relative to the cue card [object location test $(\mathrm{OL})]$ and for their memory of objects in the square [object recognition (OR) test].

turning the three screws on the rat's microdrive by between $1 / 8$ and $1 / 4$ turn and screened again the following day.

\section{Behavioral testing}

Once one or more place cells had been identified (see below, Place cell inclusion criteria), testing in the cylindrical environments began. On Day 1 , each rat was exposed for the first time to the cylinder that would be used as its familiar environment. A summary of the procedure on Day 1 is depicted in Figure $2 A$. The rat was taken from its home cage and attached to the recording cable outside the curtained enclosure. It was then placed in an opaque transport bucket and carried into the curtained enclosure where it remained for $5 \mathrm{~min}$. It was then placed into the cylinder and allowed to forage for food pellets scattered over the floor of the cylinder for a $10 \mathrm{~min}$ session (S1). After this session, the rat was returned to the bucket, where it remained for $5 \mathrm{~min}$. During this time, and before all subsequent cylinder sessions, the floor of the cylinder was wiped with a detergent-soaked cloth. The rat was then replaced in the cylinder for a second 10 min session (S2). This procedure was repeated such that the rat was exposed to the cylinder for three $10 \mathrm{~min}$ sessions, separated by $5 \mathrm{~min}$ sessions in the bucket. After the third session (S3), the rat was placed in the bucket, disconnected from the recording apparatus, and returned to its home cage. After a $6 \mathrm{~h}$ period, the rat was reconnected to the recording apparatus and reintroduced to the same environment for three additional 10 min pellet-chasing sessions separated by $5 \mathrm{~min}$ in the bucket (S4-S6). This procedure was designed to allow each rat to become habituated to the cylinder that would serve as its familiar environment. In addition, it allowed us to determine whether place fields were stable across the first three $10 \mathrm{~min}$ recording sessions in a novel environment, and also whether the place fields remained stable when returned to the same environment after a $6 \mathrm{~h}$ interval.

On Day 2 rats received further exposure to the familiar environment and were habituated to the infusion procedure. First, they received three $10 \mathrm{~min}$ sessions in the familiar cylinder, separated by $5 \mathrm{~min}$ in the bucket. Then rats were disconnected from the recording apparatus, placed in the bucket, and taken to the infusion room for mock infusions as described below. After the mock infusion, the rats were placed back into the bucket and returned to the recording room, where they were reconnected to the recording apparatus and taken into the curtained enclosure. They received three further $10 \mathrm{~min}$ pellet-chasing sessions in the familiar environment separated by $5 \mathrm{~min}$ in the bucket. The first of these sessions began $15 \mathrm{~min}$ after the beginning of the mock infusion (i.e., from when the pump was switched on). At the end of the last session, the rats were placed in the bucket, taken out of the curtained enclosure, disconnected from the recording apparatus, and returned to their home cage.

On test days (Days 3 to 7 ), the rats underwent a series of sessions to compare the effects of infusions of CNQX, D-AP5, and ACSF into the PoS on the association between place fields and landmarks in a novel environment, and on the stability of place fields in the familiar environment. The procedure adopted was the same on each day, but on each day a different novel cylinder was used, and rats received infusions of different drugs ( $2 \mathrm{~d}$ CNQX, $2 \mathrm{~d}$ D-AP5, $1 \mathrm{~d}$ ACSF) according to a counterbalanced schedule, such that different rats received different drugs on different days and in a different order. The experimenter was blind to the identity of the drug that was infused throughout data collection and initial data analysis (cluster cutting).

The procedure for each test day is summarized in Figure $2 B$. First, the rat was connected to the recording system, placed inside the bucket, and taken into the curtained enclosure where it remained for $5 \mathrm{~min}$. Then, the rat was given three $10 \mathrm{~min}$ sessions of pellet chasing within its familiar cylinder (F1-F3), each separated by a 5 min period inside the bucket. The rat was next disconnected from the recording system and transported inside the bucket to the infusion room for bilateral postsubicular infusion of CNQX, D-AP5, or ACSF as described below. The rat was then returned to the recording room, reconnected to the recording apparatus, and taken into the curtained environment in the bucket. Ten minutes after the end of the $5 \mathrm{~min}$ infusion, the rat was placed into its familiar environment for a 10 min pellet-chasing session (F4; began 10 and ended $20 \mathrm{~min}$ after end of infusion). It was then placed into the bucket for $3 \mathrm{~min}$, during which time the familiar cylinder was replaced with a novel cylinder. The rat was then given three 10 min pellet-chasing sessions in the novel cylinder (sessions N1-N3; began 23 min and ended 55 min after end of infusion), interspersed with short (1 $\mathrm{min}$ ) bucket sessions. Sessions F4 and N1-N3 all occurred within the 60-70 min period that CNQX and D-AP5 were active (see Fig. 4A). After session N3, the rat was disconnected and returned to its home cage for $6 \mathrm{~h}$. After this delay, the rat was returned to the same novel cylinder to test whether the same place fields were expressed. Two $10 \mathrm{~min}$ sessions in the novel cylinder were conducted (N4 and N5; began $\sim 7 \mathrm{~h}$ after end of infusion) separated by 5 min bucket sessions, followed by a single $10 \mathrm{~min}$ session in the familiar environment (F5). At the end of F5, the rat was disconnected from the recording cable and returned to its home cage. Sessions N4, N5, and F5 all occurred when the drugs were no longer effective (see Results, Experiment 1). During behavioral testing, single unit and position data was collected for every $10 \mathrm{~min}$ pellet-chasing session in the cylindrical environments.

\section{Infusion procedures}

PoS infusions were performed in a room that was separate from the behavioral testing rooms. Each rat was wrapped loosely in a towel and placed on the experimenter's lap. Both dummy injectors were removed, and two infusion cannulae were inserted into the guide cannulae in their place. Each infusion cannula was connected to a glass syringe ( $5 \mu \mathrm{l}$; SGE) mounted onto a microinfusion pump (Sp200i syringe pump; World Precision Instruments) via a length of plastic tubing (PKG Tubing PE20; Plastics One). For infusion trials, the plastic tubing and infusion cannulae were preloaded with ACSF, CNQX, or D-AP5. The pump was then turned on, depressing the two syringes such that $1 \mu \mathrm{l}$ of the compound 
was infused simultaneously into the PoS bilaterally over a 5 min period at a rate of $0.2 \mu \mathrm{l} / \mathrm{min}$. For mock infusion trials, the tubing and infusion cannulae were not preloaded, and although the pump was switched on, the pump was configured in such a way that the syringes were not depressed. After the infusion (or mock infusion), the pump was switched off and the rat remained on the experimenter's lap for a further $2 \mathrm{~min}$ before the infusion cannulae were removed and the dummy injectors replaced after being cleaned using 95\% alcohol, rinsed with saline, and dried.

\section{Data analysis}

The activity of individual neurons was isolated off-line in two steps. First, using all of the cylinder sessions recorded on a day for a given animal, automated clustering using energy and first principal component was conducted using the Matlab-based (MathWorks) spike-sorting software KlustaKwik 1.5 (K. Harris, Rutgers University, Newark, NJ; http://klustakwik.sourceforge.net). After this, these clusters were refined by manual clustering using Klusters (L. Hazan, Rutgers University, Newark, NJ; klusters.sourceforge.net). Manual clustering involved inspecting the automatically clustered waveforms and the auto- and crosscorrelograms of these clusters and refining them using energy, first principal component, and additional parameters including spike height, valley, and width.

Firing rate maps for each neuron were based on Leutgeb et al. (2007). Each 10 min cylinder session was divided into $5 \times 5 \mathrm{~cm}$ bins, and the average firing rate of the neuron in each bin was calculated by dividing the total number of spikes in the bin by the total time the animal spent in the bin. This was then smoothed using a Gaussian kernel, $g(x)=\exp$ $\left(-x^{2} / 2\right)$ (Huang, 2010).

Place cell inclusion criteria. Neurons were categorized as putative place cells if, after clustering, they fulfilled two criteria: the average peak amplitude on at least one wire was $>80 \mu \mathrm{V}$, and the average width of largest waveform (peak to trough) was $>250 \mu \mathrm{s}$. A putative place cell was considered to be silent in a given cylinder session if its average firing rate in that session was $<0.1 \mathrm{~Hz}$. It was considered to express a place field in a given cylinder session if its average firing rate was between 0.1 and $5 \mathrm{~Hz}$ and the Skaggs spatial information content (Markus et al., 1994) was $>0.5$ in that session. Only cells that expressed place fields in at least one cylinder session were considered for subsequent analyses.

Comparison of firing rate maps between sessions. To compare the firing rate maps of a given neuron between pairs of sessions, we calculated the Pearson product-moment correlation coefficient $r$ between the two firing rate maps. A neuron was included in this analysis if it expressed a place field in at least one of the two sessions being compared. This allows for the possibility that a place cell could express a place field in one session of the pair but not in the other (a form of remapping).

\section{Histology}

At the completion of the study, animals were given an overdose of pentobarbital solution (Euthatal; Merial Animal Health) and transcardially perfused with saline, followed by a $4 \%$ formaldehyde solution. The brains were removed and stored in the formaldehyde solution until undergoing histological processing. This processing comprised taking 30 $\mu \mathrm{m}$ brain sections with a freezing microtome and using standard Nisslstaining procedures to visualize electrode and cannula placements.

\section{Experiment 3 \\ Animals}

Thirty-four rats, weighing 250-350 g at the time of surgery, were housed in group cages (three or four per cage). Before surgery, and during recovery, all rats had unrestricted access to food and water. Two weeks after recovery from surgery, rats continued having unrestricted access to water, but were food restricted to around $90 \%$ of their ad libitum body weight.

\section{Apparatus}

Object recognition arena. Object recognition memory was tested within a circular arena (76 cm diameter with 40-cm-high walls). The arena floor was wood and painted black. The arena walls were made of brown, wood- effect, sticky-backed plastic wall affixed to a wire mesh frame. Two Dual Lock (hook-and-loop fasteners; $3 \mathrm{M}$ ) pieces were fixed to the floor of the arena, $10 \mathrm{~cm}$ from the walls in the northeast and northwest corners of the box, and $23 \mathrm{~cm}$ apart. These were the positions in which objects could be presented. The object recognition arena was separated from the rest of the laboratory room within a square, curtained enclosure $(1 \times 1 \mathrm{~m})$. The enclosure was made from one black and three white curtains, each of which stretched from the ceiling to the floor. Salient, three-dimensional landmarks, including a rainbow-colored feather duster and a large plastic flower, were attached to the curtains. An overhead video camera (Panasonic) was fixed centrally above the arena through a slit in a curtain that enclosed the roof of the enclosure, and the video signal fed into a DVD recorder and a PC equipped with an in-house timing computer program (written by P. Spooner, using LabView, National Instruments).

Object-location arena. The object-location-recognition memory task was conducted in a separate circular arena in the same room as the object recognition arena. The object-location arena $(68 \mathrm{~cm}$ diameter cylinder with 50 -cm-high walls) was plastic, painted gray, and contained a white cue card $(21 \mathrm{~cm}$ wide by $50 \mathrm{~cm}$ tall) that covered an 112 degree segment of the cylinder walls. As in traditional hippocampal place cell recording experiments (Muller and Kubie, 1987), this cue was designed to serve as a polarizing spatial landmark within the arena. Six small strips of Dual Lock were attached the floor of the arena, $10 \mathrm{~cm}$ from the walls, and spaced equidistantly in a circle. These served as the potential locations for objects during the task. The object-location arena was enclosed by three black curtains arranged in a circle, which stretched from the near the base of the arena to a false ceiling. Access to the arena was possible at the three overlapping sections of the three curtains comprising the enclosure. Approximately centered in the false ceiling were a video camera, a light, and a radio that was tuned off-channel, and served to mask uncontrolled sounds in the environment.

\section{Procedure}

Habituation. Before recognition memory testing, four habituation sessions (one per day) were performed to familiarize the rats to the two testing arenas. For the first habituation session (Day 1) rats were placed into the object-location arena with their cage mates and were allowed to explore the arena in the absence of objects for $30 \mathrm{~min}$ before being placed in the holding bucket and transferred into the object recognition arena for another $30 \mathrm{~min}$ period of exploration. The following three habituation sessions (Days 2-4) were run in a similar manner, except that the rats were placed into each arena (object-location arena followed by object recognition arena) individually for $10 \mathrm{~min}$. Following the $10 \mathrm{~min}$ exploration period in the object recognition arena, the rat was placed into the holding bucket for a further $10 \mathrm{~min}$, after which it was returned to its home cage. On each of the individual habituation sessions (Days 2-4), the rats entered the object-location arena via a different slit in the curtains surrounding the arena and were placed facing the wall adjacent to that slit. Entry to the object recognition arena was always from the south side, and animals were always placed facing the middle of the south wall. Both arenas were wiped clean using warm soapy water between rats.

Object and object-location memory. Following habituation, rats received nine trials on the object- and object-location recognition memory tasks. Each trial was run over $2 \mathrm{~d}$, with the memory encoding phase for both tasks taking place on the first day, and the memory tests for both tasks occurring $24 \mathrm{~h}$ later. The procedure for each trial is illustrated in Figure $2 C$. During the memory encoding phase, the rat received three 5 min sample periods in the object-location arena, alternating with three 5 min sample periods in the object recognition arena, for a total memory encoding phase of $30 \mathrm{~min}$ ( $15 \mathrm{~min}$ for each task). The object-location arena contained two novel objects, each affixed to one of the six Dual Lock floor strips. The object recognition arena contained two copies of a third novel object, one on each of the Dual Lock floor strips. The same objects were located in the same locations during each of the three sample periods in each box. The arenas and objects were wiped with a dilute solution of washing-up liquid after each 5 min sample period. Memory testing took place $24 \mathrm{~h}$ after the memory encoding phase. Rats were placed first in the object-location arena for $5 \mathrm{~min}$, and then for $5 \mathrm{~min}$ in the object recognition arena. In the object-place arena, the same objects 

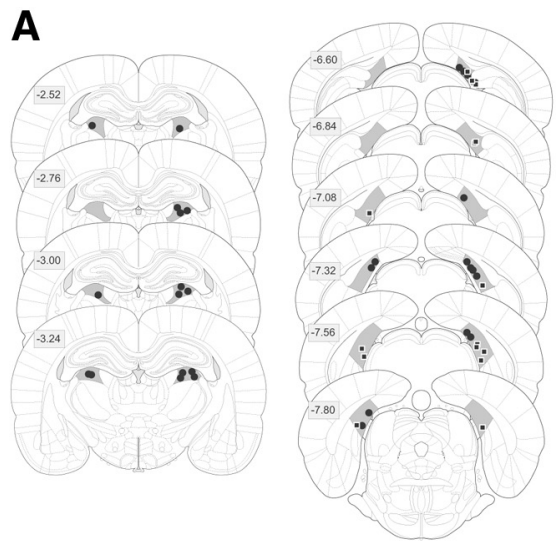

B

C
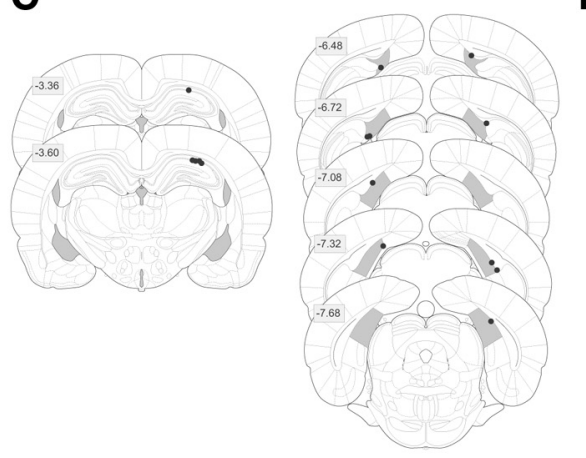

D
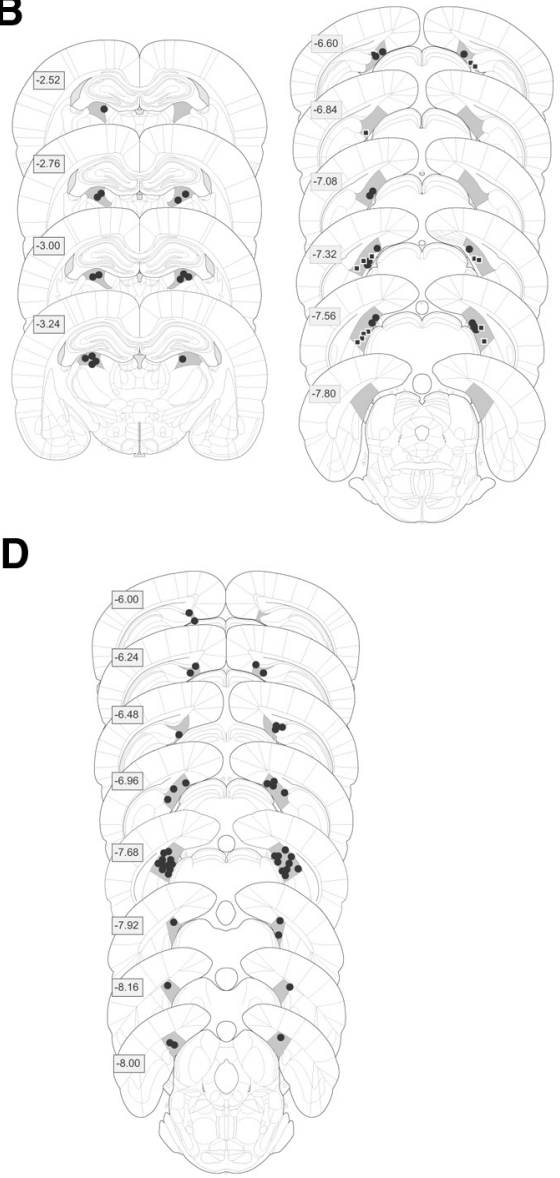

Figure 3. $A-D$, Schematic illustration of the locations of the tips of cannulae, recording electrodes, and stimulation electrodes from Experiments 1 ( $\boldsymbol{A}$, effects of drug infusions on synaptic transmission; $\boldsymbol{B}$, effects of drugs on LTD), 2 ( $\boldsymbol{C}$, effects of drug infusions on place cell activity), and 3 ( $D$, effects of drug infusions on recognition memory). $A, B$, Experiment 1. Left, Locations of tips of stimulating electrodes in the LDN; each black dot represents one electrode tip. The shaded area is the LDN. Right, Locations of tips of recording electrodes (black dots) and infusion cannulae (black squares) in PoS. C, Experiment 2. Left, Locations of recording electrodes (black dots) in CA1 cell layer of hippocampus (black dots). Right, Locations of tips of infusion cannulae (black dots) in P0S (shaded area). D, Experiment 3. Locations of tips of infusion cannulae (black dots) in PoS (shaded area).

from the previous day were present, one in the same location and one in a different location relative to the cue card. Preferential exploration of the displaced object suggests that the rat has detected the novel placement of the object and thus remembers each object's original position. In the object recognition arena, one of the two identical objects was replaced with a novel object. Preferential exploration of the novel object indicates that the rat recognizes the object that it had seen the day before.

On the first two trials (preinfusion trials), rats received no drug infusions. These trials were to familiarize the animals with the behavioral procedures that would be used, and to reduce any neophobia to objects. On the third trial, they received a 5 min mock infusion (as described for Experiment 2) ending $10 \mathrm{~min}$ before the first sample period of the memory encoding phase. This was included to familiarize the animals with the infusion procedure. On Days 4, 6, and 8, the rats received a 5 min postsubicular infusion of ACSF, D-AP5, or CNQX ending 10 min before the first sample period of the memory encoding phase. Thus, all of the encoding sessions occurred during the period when the CNQX and D-AP5 were active, whereas the $24 \mathrm{~h}$ memory test took place when the compounds were no longer active (see Results, Experiment 1). Each rat received one trial with each compound, and the order of compounds delivered across the three drug infusion days was counterbalanced across rats. On Days 5, 7, and 9 (noninfusion trials) rats received no drug infusions. The experimenter was blind to the infusion condition for the duration of behavioral testing and object-exploration scoring.

\section{Scoring, inclusion criteria, and} data analysis

Object exploration was scored for each object during each 5 min sample period and each 5 min test period. Scoring was conducted online using the in-house software, and involved monitoring the rat's behavior on a video monitor and making key presses that activated timers for each object. A rat was considered to be exploring an object if its snout was directed toward the object and was within a $2 \mathrm{~cm}$ radius of the object, and if the rat was involved in sniffing or whisking behavior. A given trial was included for analysis only if rats spent at least $15 \mathrm{~s}$ exploring each object across the three sample phases, and at least $10 \mathrm{~s}$ exploring both objects (combined total) in the test phase. On the few occasions on which these criteria were not reached, the trial was repeated on a different day using different objects.

Memory in the test phase was operationalized as a preference for exploring the displaced object compared to the object that had not been moved in the object location task, and a preference for exploring the novel object compared to the previously seen object in the object-recognition task. Two methods were used to make these comparisons. The first was a simple comparison of the total amount of time spent exploring each object in the test phase. The second was to convert the test phase exploration times into a discrimination ratio for each trial, defined as (exploration of novel or displaced object minus exploration of familiar or stable object)/total object exploration.

\section{Histology}

At the completion of testing, cannulae placements were verified using the same procedures as described for Experiment 2.

\section{Results}

\section{Experiment 1}

\section{Histology}

In both the synaptic transmission (Fig.

$3 A)$ and synaptic plasticity $(B)$ experiments, all stimulating electrodes were correctly positioned in the LDN (left-hand panels), and all recording electrodes and ipsilateral infusion cannulae were located in the postsubiculum (righthand panels).

\section{Infusions of CNQX in the postsubiculum inhibited} evoked responses

Infusion of ACSF had no effect on baseline synaptic transmission between the LDN and PoS, and D-AP5 caused only a small, transient reduction in the size of fEPSPs, comparable to that seen in the hippocampus following direct infusion in vivo (Bast et al., 2005). In contrast, infusion of CNQX resulted in a large decline in fEPSP amplitude, with values rapidly falling to $<40 \%$ of baseline toward the end of the infusion period and remaining at this level for $>60 \mathrm{~min}$ (Fig. $4 A$ ). Figure $4 B$ shows examples of fEPSPs taken from one member of each drug infusion group $\sim 10$ min before the start of infusion, and 10, 40,60, and 90 min after the end of infusion. Note the transient fall in fEPSP amplitude following D-AP5 infusion, and the pronounced fall induced by CNQX, followed by a recovery to near-baseline levels by $90 \mathrm{~min}$. Figure $4 C$ shows mean fEPSP amplitude 5-10, 35-40, and 55-60 min after 

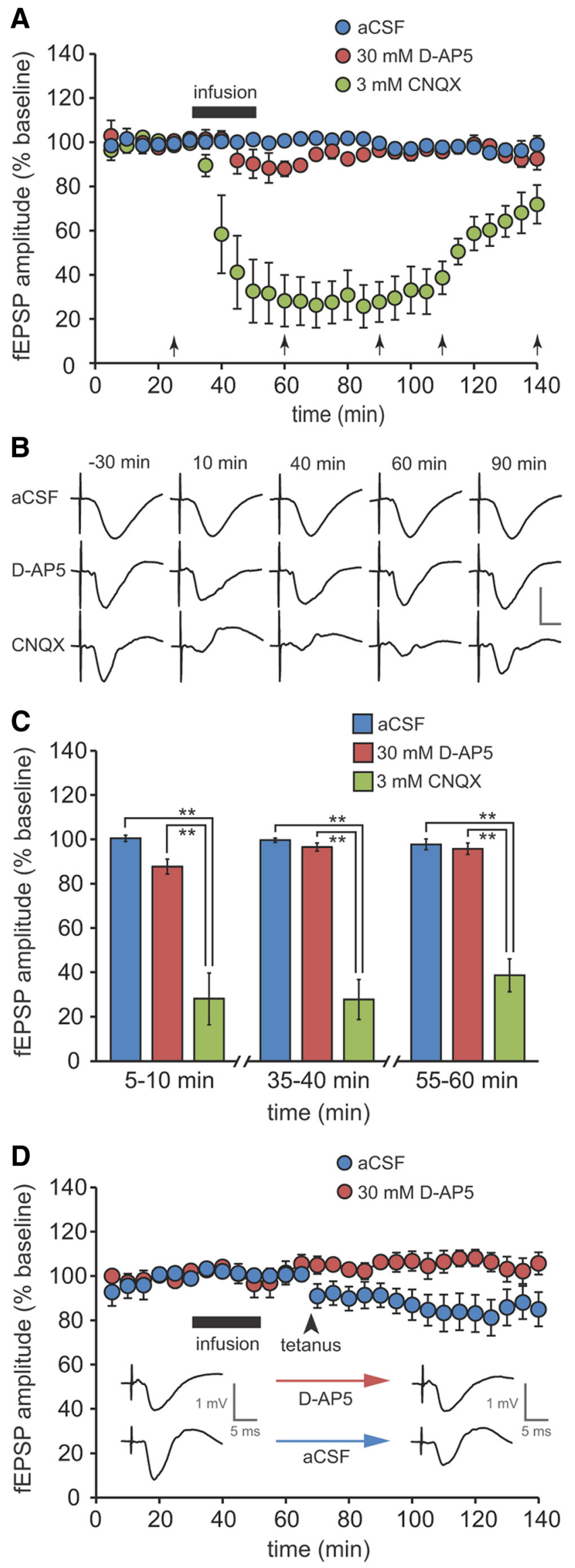

the end of infusion (i.e., corresponding to the middle three time points in Fig. 4B). ANOVAs of fEPSP amplitude revealed significant group differences at each point $\left(5-10 \mathrm{~min}, F_{(1,12)}=38.591\right.$, $p<0.0005 ; 35-40 \mathrm{~min}, F_{(1,12)}=21.627, p<0.0005 ; 55-60 \mathrm{~min}$, $\left.F_{(1,12)}=38.831, p<0.0005\right)$. Post hoc pairwise comparisons (Fisher's LSD) revealed significant differences in normalized fEPSP amplitude between ACSF and CNQX, and between D-AP5 and CNQX groups ( $p<0.0005$ in all cases), but no significant differences between D-AP5 and ACSF groups $(p>0.3$ in all cases). A substantial recovery of fEPSPs was evident in the CNQX group by the end of the experiment. However, an ANOVA of fEPSP amplitude 85-90 min after the end of infusion still revealed a main effect of group $\left(F_{(2,12)}=4.18, p<0.05\right)$, and post hoc comparison of ACSF and CNQX groups indicated a significant difference ( $p<0.05$; Fisher's LSD). The difference between AP5 and CNQX groups did not reach significance $(p>0.05)$. In three CNQX-treated animals, longer-duration recordings revealed a full return to baseline values within $\sim 2.5 \mathrm{~h}$ of infusion (data not shown).

Infusions of D-AP5 in the postsubiculum blocked

long-term depression

Tetanization at $60 \mathrm{~Hz}$, applied $15 \mathrm{~min}$ after the end of ACSF infusion, resulted in a modest LTD of fEPSP amplitude. This LTD was completely blocked by prior infusion of D-AP5 (Fig. 4D). Over the last $30 \mathrm{~min}$ of recording (45-75 min after tetanus), fEPSP amplitude was significantly lower in the ACSF compared to the D-AP5 group $\left(t_{(13)}=2.25, p<0.05\right.$; Fig. $\left.4 D\right)$.

\section{Experiment 2}

The aim of Experiment 2 was to determine whether blocking NMDAR-mediated synaptic plasticity or AMPA/KA-R-mediated synaptic activity in PoS affected the formation or stability of hippocampal place fields recorded in CA1 in a novel environment. We also assessed whether the same infusions affected place field stability in a familiar environment.

\section{Histology}

Histological analysis of the brains revealed that the cannulae tips were accurately located, bilaterally, within the postsubiculum for all five rats. The cannulae tip locations are shown in Figure $3 C$ (right). Inspection of tracks made by the tetrode bundle revealed that all recordings were from cells in the CA1 cell layer of the dorsal hippocampus, as shown in Figure $3 C$ (left).

Place fields are stable across repeated sessions in a novel environment

On Day 1, CA1 pyramidal cell activity was recorded as rats were exposed for the first time to what would become their familiar environment. Rats received six 10 min sessions in this environ-

$\leftarrow$

Figure 4. Effects of excitatory glutamate receptor antagonists on synaptic transmission and plasticity in the LDN-postsubiculum projection. $A$, Direct postsubicular infusion of CNQX caused a marked reduction in the amplitude of fEPSPs, whereas D-AP5 caused only a small and transient fall; ACSF had no effect (ACSF, $n=4 ; \mathrm{D}-\mathrm{AP5}, n=5$; CNQX, $n=6$ ). $\boldsymbol{B}$, Representative examples of fEPSPs recorded at five different time points (indicated by arrows above the $x$-axis in $\boldsymbol{A}$ ) relative to the end of drug infusion. $C$, Mean normalized fEPSP amplitude in all groups 5-10 min, 35- 40 min, and 55- 60 min after the end of infusion (ACSF, $n=4 ; 0-A P 5, n=5$; CNQX, $n=6$; $\left.{ }^{* *} p<0.01\right)$. D, Synaptic plasticity in the LDN-postsubiculum projection is NMDA receptor dependent: intermediate-frequency tetanization of the LDN ( 2 trains of 120 pulses at $60 \mathrm{~Hz} ; 60$ s intertrain interval) after ACSF infusion caused a modest depression of fEPSP amplitude; this depression was completely blocked by prior infusion of D-AP5 (ACSF, $n=8$; D-AP5, $n=7$ ). Representative examples of fEPSPs recorded before and $>60 \mathrm{~min}$ after tetanization are shown. Error bars indicate SEM. 
A
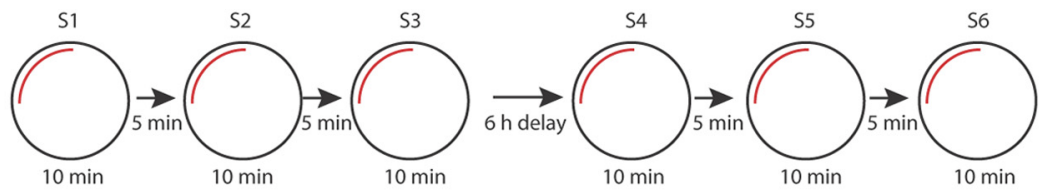

B Cell 1 - 09049 t1c3
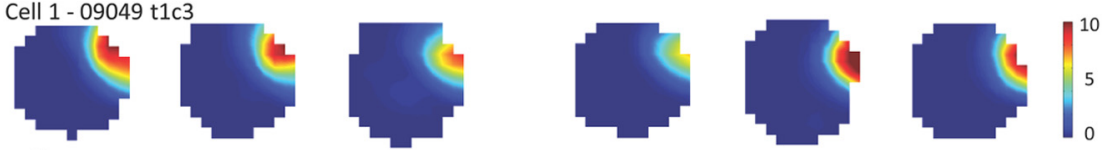

Cell 209049 t4c6
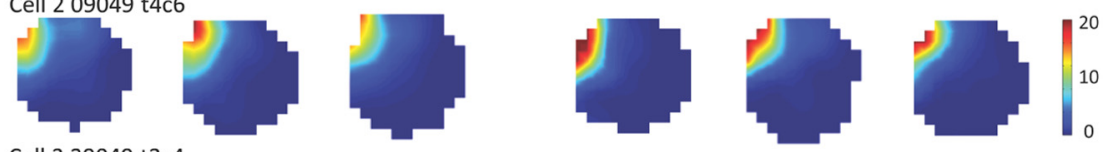

Cell 329049 t3c4
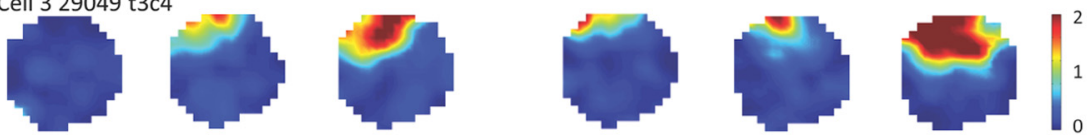

Cell 420059 t2c3
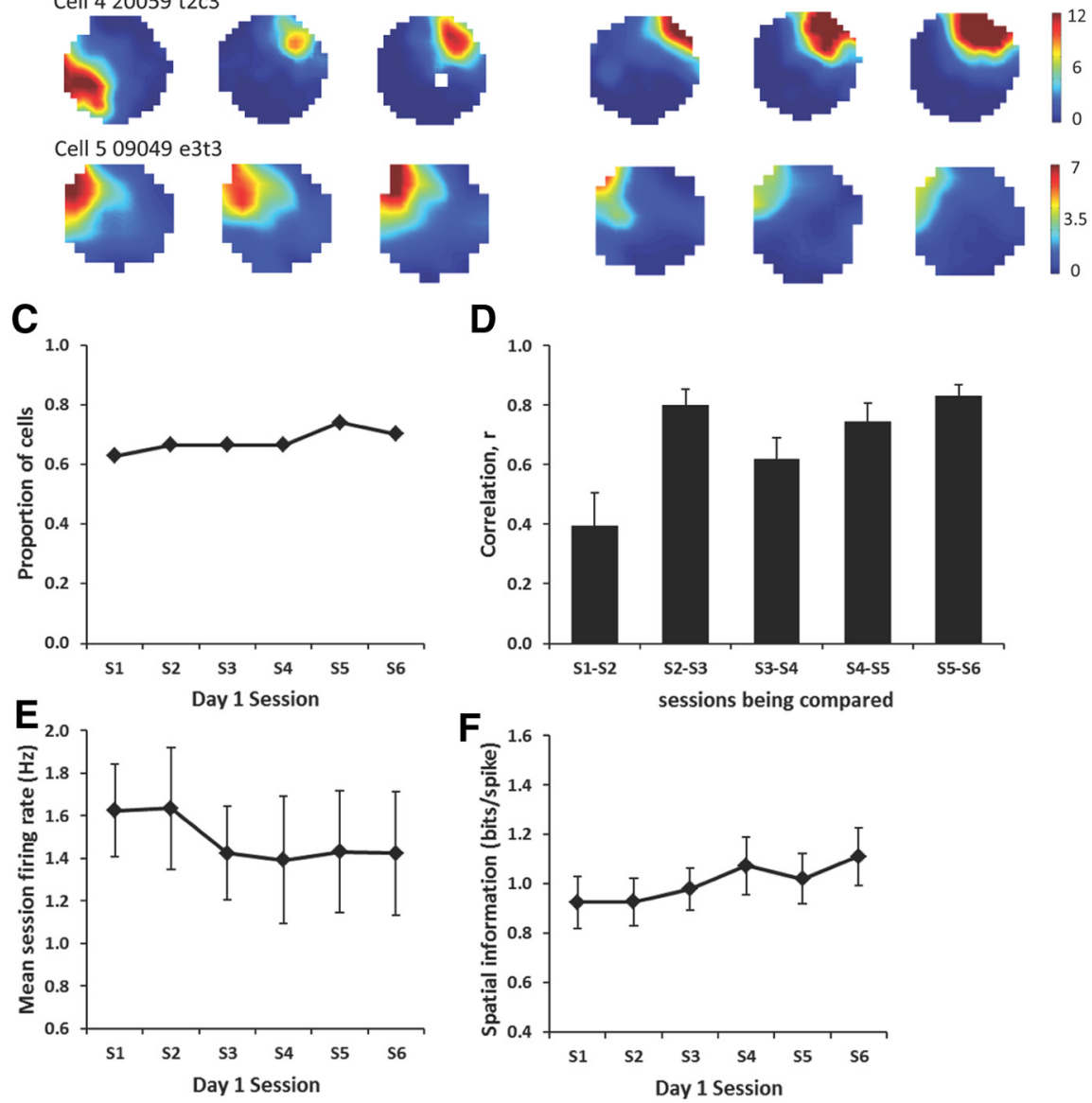

D
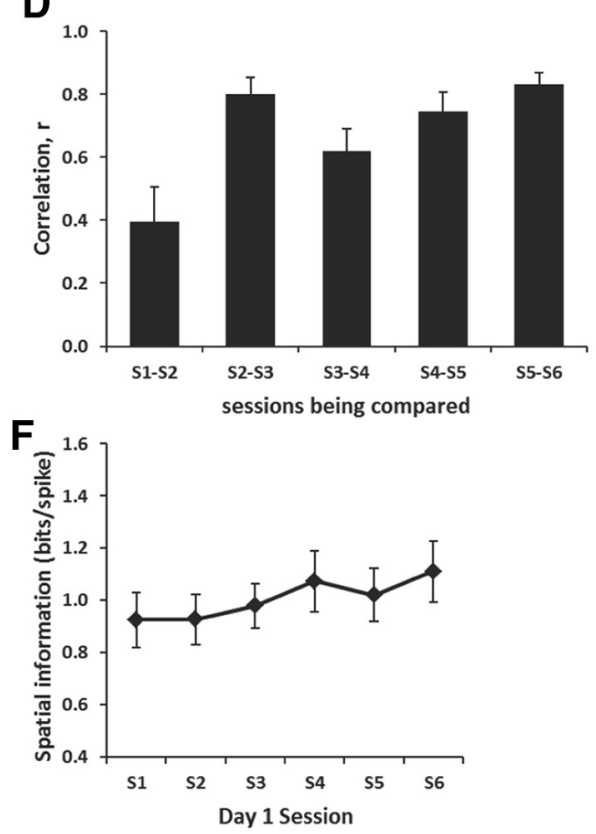

Figure 5. Placecell stability in repeated recording sessions in a single environment. $A$, Recording session sequence. $B$, Examples of firing rate maps from five place cells across the six 10 min recording sessions on Day 1. Each row depicts the maps from one cell across the five sessions (S1-S6). C, The proportion of cells with place fields was similar across all six sessions. D, There was a tendency for firing rate maps to be less correlated in the first two recording sessions (S1-S2) compared to other sessions. The correlations between firing rate maps before and after the $6 \mathrm{~h}$ delay $(S 3-S 4)$ was also somewhat lower than subsequent correlations. $E$, Mean firing rates did not differ across sessions. $\boldsymbol{F}$, Spatial information did not differ across sessions. Error bars indicate SEM.
Cell 509049 e3t3

observed during the first 10 min exposure to an environment ( $\mathrm{S} 1$; Cells 1, 2, 4, and 5 ), and that from $\mathrm{S} 2$ the cells typically fire in the same location in the subsequent five sessions. In total, 27 cells recorded from five rats were categorized as place cells in one or more sessions on Day 1. Overall, the proportion of cells classified as expressing place fields remained the same across sessions (Fig. 5C; Pearson's $\chi^{2}=$ $1.288, \mathrm{df}=5, p=0.936$ ). To determine whether the spatial activity of the place cells was stable across sessions, pairwise correlations between firing rate maps were performed for each cell between consecutive sessions (S1 and S2, S2 and S3, etc.; Fig. 5D). A one-way ANOVA revealed that the correlations between consecutive pairs of sessions differed significantly $\left(F_{(4,99)}=6.212, p<0.01\right)$. Post hoc pairwise comparisons (LSD) revealed that the correlation between the first and second exposures to the environment (S1-S2) was significantly lower than that between the second and third exposures (S2-S3) and between all subsequent pairs of sessions ( $p$ values $<0.05$ ). However, from the second session onward, the correlations between consecutive sessions did not differ significantly. Thus, it appears that the place fields were stable by the end of the second 10 min exposure (S2), as the same place fields were expressed 10 min later (S3), and these fields typically remained stable over a 6 h delay period (S3-S4). The correlation between S3 and S4 (with a $6 \mathrm{~h}$ delay between sessions) is slightly lower than those for S2-S3 and S4-S5 (which are only separated by $5 \mathrm{~min}$ ), although this difference did not reach significance.

Mean firing rates and spatial information of the cells that were classified as place cells in each session are shown in Figure 5, $E$ and $F$, respectively. Mean firing rates tended to decrease, and spatial information tended to increase across sessions, consistent with previous reports of refinement of spatial codes with experience (Frank et al., 2004). However, one-way ANOVAs indicated that neither of these measures varied significantly as a function of session (firing rate, $F_{(5,104)}=0.161, p=$ 0.976 ; spatial information, $F_{(5,104)}=$ $0.532, p=0.752$ ).

The data collected during Day 1 provided baseline measures of firing rates, ment (S1-S6), with short (5 min) intervals between S1, S2, and $\mathrm{S} 3$; a $6 \mathrm{~h}$ interval between $\mathrm{S} 3$ and $\mathrm{S} 4$; and short intervals between $\mathrm{S} 4, \mathrm{~S} 5$, and $\mathrm{S} 6$ (Figs. $2 B, 5 A$ ). Five examples of firing rate maps from these sessions are shown in Figure $5 B$. Each row shows the firing rate maps for a single cell during the six $10 \mathrm{~min}$ recording sessions (S1-S6) on Day 1. These maps reveal that place fields are spatial information, and place field stability observed during the first day's exposure to a novel environment. From these data, we determined that a stable representation of a novel environment capable of being maintained over a short interval $(5 \mathrm{~min})$ is formed after two $10 \mathrm{~min}$ exposures (as supported by the high spatial correlations between S2 and S3). Moreover, after three 10 
min exposures, the representation is capable of being retained over a $6 \mathrm{~h}$ delay. This was therefore the protocol used in the drug infusion studies that follow.

CNQX but not D-AP5 infusions into postsubiculum cause hippocampal place cells to remap in a familiar environment On test days, animals received 10 sessions in total, 5 in the now familiar environment and 5 in a novel environment (Fig. $2 B$ ). The numbers of recorded cells categorized as place cells in one or more of these sessions across the five rats were 16 for the ACSF condition, 30 for the D-AP5 condition, and 33 for the CNQX condition. We first analyzed the effects of bilateral infusions of CNQX, D-AP5, and ACSF into the postsubiculum on hippocampal place cell activity and place field stability in the familiar environment. As shown in Figure $6 A$, the five sessions in the familiar environment were as follows: F1-F3 occurred before the infusion, F4 occurred 10 min after the end of the infusion (when the compounds should have been active), and F5 occurred $>7 \mathrm{~h}$ after the infusion (by which time their effects should have worn off). Example firing rate maps from these sessions are shown in Figure $6 B$, with each row depicting a different cell recorded in sessions F1-F5. Before the infusions (session F1-F3), the place fields were generally stable in the familiar environment in all three infusion conditions, with no significant differences observed in the correlations between the last two sessions before infusion (F2 and F3) between the three drug conditions (Fig. $6 B, C ; F_{(2,52)}=$ $0.507, p=0.61)$. In contrast, while most cells continued to fire in a similar location in F4 following ACSF and D-AP5 infusions (Fig. 6B; ACSF, Cells 1, 2, and 4; D-AP5, Cells 1-5), CNQX infusions resulted in remapping in many cells (Fig. 6B; CNQX, Cells 2-5).

To quantify this, we counted the number of cells that showed a low correlation $(r<0.2)$ between sessions F3 (before drug infusion) and F4 (15 min after drug infusion). For CNQX, 63\% of cells showed this remapping between F3 and F4. In contrast, only $23 \%$ and $19 \%$ remapped in the ACSF and D-AP5 conditions, respectively. These proportions differed significantly among the three groups (Pearson's $\chi^{2}=$ $11.378, \mathrm{df}=2, p<0.005)$, and subsequent analyses revealed that the proportion of cells remapping in the CNQX condition was significantly greater that in the ACSF and D-AP5 conditions (ACSF vs CNQX, Pearson's $\chi^{2}=5.584, \mathrm{df}=1, p<0.05$; D-AP5 vs CNQX, Pearson's $\chi^{2}=9.257, \mathrm{df}=1, p<0.01$ ), and that the ACSF and D-AP5 conditions did not differ from each other (ACSF vs D-AP5, Pearson's $\chi^{2}=0.08, \mathrm{df}=1, p=0.778$ ).

A
B

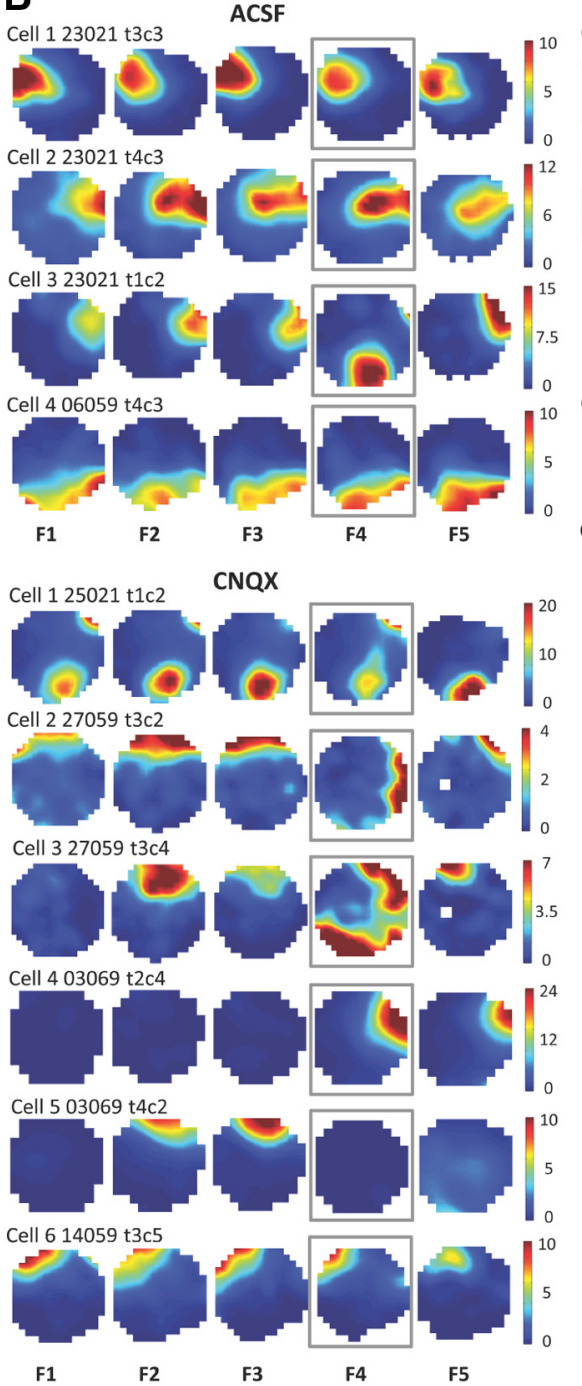

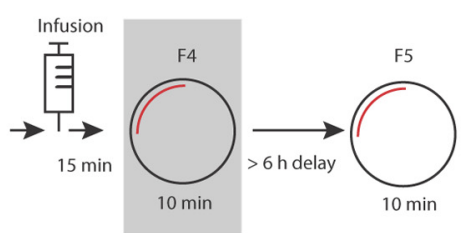

D-AP5
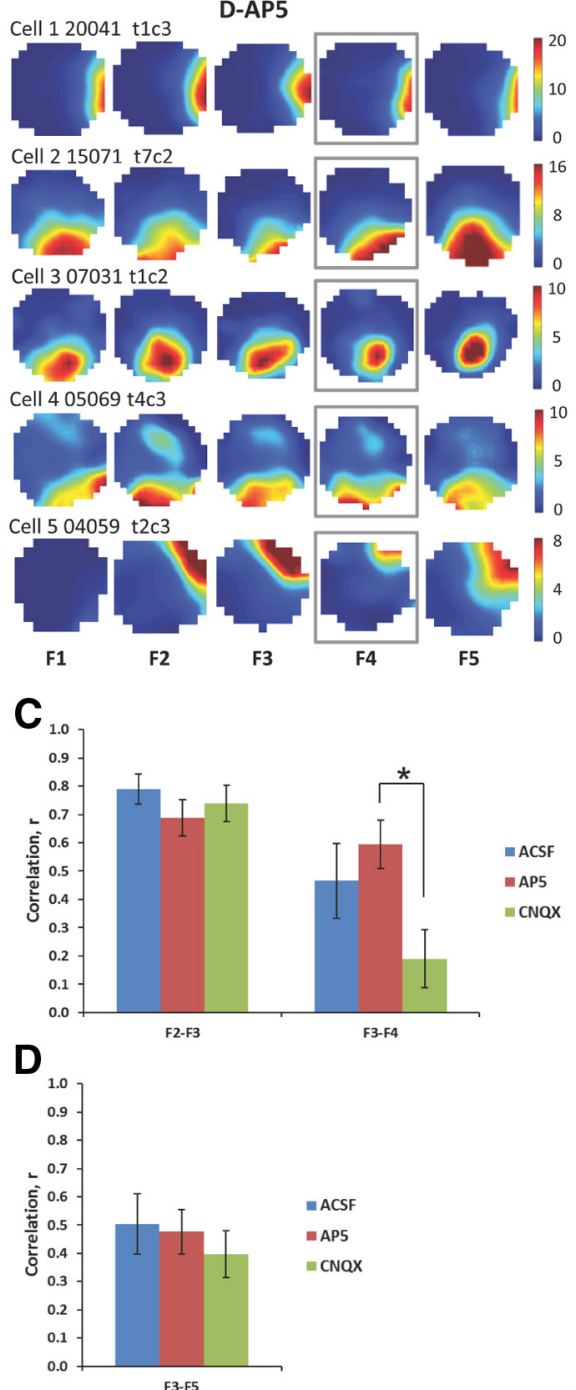

Figure 6. Place cell recordings in a familiar environment before and after infusions into the postsubiculum. $\boldsymbol{A}$, Familiar environment session sequence (novel sessions not shown). Shaded sessions (F4) took place while drugs were active. $\boldsymbol{B}$, Examples of firing rate maps in the familiar environment before (F1-F3), 10 min after (F4), and $>7$ h after (F5) infusion of ACSF, D-AP5, or CNQX into postsubiculum. Each row depicts the firing rate maps of one cell across the five sessions. Boxes around session F4 indicate period when drug was active. $C$, Infusions of CNQX reduced the correlation between firing rate maps before and after infusion (F3-F4), when compared to D-AP5 ( $\left.{ }^{*} p<0.05\right)$ or to the predrug sessions (F2-F3). D, Infusions of CNQX and D-AP5 into postsubiculum did not affect the long-term stability of place fields in the familiar environment. The correlation between firing rate maps before infusion (F3) and $7 \mathrm{~h}$ after infusion (F5) did not differ significantly in the three infusion conditions. Error bars indicate SEM.

A largely similar outcome was observed using a different type of analysis. The correlations between the firing rate maps in sessions F3 and F4 differed significantly among the three drug conditions (Fig. 6C; one-way ANOVA, $F_{(2,57)}=4.593, p<0.05$ ). As above, post hoc pairwise comparisons (Fisher's LSD) revealed that the F3-F4 correlations were significantly lower in the CNQX infusion condition than in the D-AP5 infusion condition ( $p=$ $0.004)$, ACSF did not differ from D-AP5 $(p=0.467)$, but the difference between CNQX and ACSF did not reach significance $(p=0.105)$. To explore whether the F3-F4 correlations were 
significantly different from the F2-F3 correlations (before drug infusion) in the three infusion conditions, we conducted a twoway ANOVA with infusion condition and session comparison (F2-F3 and F3-F4) as the independent variables. This revealed a significant main effect of session comparison $\left(F_{(1,108)}=17.148\right.$, $p<0.001)$ and a significant interaction $\left(F_{(2,108)}=3.875, p=\right.$ $0.024)$, but no significant main effect of drug infusion $\left(F_{(2,108)}=\right.$ $2.706, p=0.071)$. Individual comparisons for each drug infusion condition showed that the F2-F3 and F3-F4 correlations did not differ significantly for the D-AP5 condition $(p=0.377)$. However, there was a significant decrease in stability in the CNQX condition $(p<0.001)$, and a smaller but significant decrease in the ACSF condition $(p=0.035)$. The latter effect may indicate that some aspect of the procedure (removal from the room, attachment to the injection cannulae, and administration of a substance into the PoS) had a general effect on the place cell map. However, the degradation of the place cell map following the administration of CNQX was much more dramatic than following ACSF. Whereas ACSF F2-F3 and F3-F4 correlations were 0.79 and 0.47 , respectively, the corresponding correlations for CNQX were 0.74 and 0.19 .

Together, these data suggest that blocking synaptic activity in PoS with CNQX may disrupt retrieval of the previously formed representation of the familiar environment, resulting in remapping, whereas blocking NMDAR-mediated processes does not.

To determine whether the infusions had long-term effects on place cell stability in the familiar environment, we compared the correlations between F3 (before infusion) and F5 ( $>6 \mathrm{~h}$ after infusion) across conditions. Although some cells in the CNQX infusion condition that remapped in $\mathrm{F} 4$ showed similar fields in F5 (Fig. 6B; Cells 4, 5), others reverted to their original fields in F5 (Fig. 6B; Cells 2,3). Analyzing across all the cells, it can be seen in Figure $6 D$ that all three infusion conditions resulted in similar correlations between F3 and F5 $\left(F_{(2,58)}=0.398, p=0.67\right)$. In other words, after the $6 \mathrm{~h}$ delay, the cells tended to adopt the fields expressed before the drug infusion in all three infusion conditions. This suggests that, despite temporary disruption of the place field representation of the familiar environment during the period when CNQX was active in PoS, temporary disruption of synaptic activity in PoS did not significantly disrupt the longterm stability of the place fields that had been formed previously in the familiar environment.

Additional analyses indicated that infusion of CNQX had no effect on place cell firing rates or spatial information scores, and that the lower correlation following CNQX infusions was the result of remapping rather than a change in the proportion of cells expressing place fields. There were no significant differences in mean firing rates between F3 and F4 for any drug (analysis conducted on all cells that show a place field in either F3 or F4; main effect of session, $F_{(1,148)}=0.007, p=0.936$; main effect of drug infusion condition, $F_{(2,148)}=0.354, p=0.703$; interaction, $F_{(2,148)}=0.137, p=0.872$; data not shown). Likewise, there were no differences in mean firing rates and spatial information of each cell classified as a place cell in sessions F3 (before infusion), F4 (infusion), and F5 ( $>6 \mathrm{~h}$ after infusion; firing rate, session effect, $F_{(2,138)}=0.582, p=0.56$; drug infusion effect, $F_{(2,138)}=$ $0.100, p=0.905$; interaction, $F_{(4,138)}=0.327, p=0.859$; spatial information, session effect, $F_{(2,138)}=1.688, p=0.189$; drug infusion effect, $F_{(2,138)}=2.538, p=0.083$; interaction, $F_{(4,138)}=$ $0.503, p=0.734)$. One-way ANOVAs comparing mean firing rates and spatial information just in session F4 (when the drugs would have been acting) also revealed no differences in the drug infusion condition on either measure (firing rate, $F_{(2,43)}=0.522$, $p=0.597$; spatial information, $\left.F_{(2,43)}=1.669, p=0.200\right)$. Finally, a similar proportion of place cells exhibited place fields in session F3 (before infusion) and in session F4 (while compounds were active) in the three infusion conditions (F3, Pearson's $\chi^{2}=$ 0.387, $\mathrm{df}=2, p=0.824 ; \mathrm{F} 4$, Pearson's $\chi^{2}=1.318, \mathrm{df}=2, p=$ 0.517). Moreover, a similar proportion of cells exhibited place fields in both F3 and F4 in the three infusion conditions (Pearson's $\left.\chi^{2}=0.156, \mathrm{df}=2, p=0.925\right)$.

A previous study by Calton et al. (2003) found that a significantly higher proportion of place fields in animals with PoS or anterior dorsal thalamic lesions showed increased directional modulation of firing (as indexed by directional information content). In the current study, it was not possible to assess this unambiguously, as a single spot video tracking system was used.

Place cells show similar remapping and place field activity in a novel environment following ACSF, CNQX, and D-AP5 infusions into PoS

Next, we analyzed the effects of bilateral infusions of CNQX, D-AP5, and ACSF into the postsubiculum on the ability of hippocampal place cells to form place fields in a novel environment. On test days rats received five sessions in the novel environment: N1-N3 occurred between 28 and $60 \mathrm{~min}$ after the drug infusions (when the compounds should have been active; Fig. 4A), whereas $\mathrm{N} 4$ and $\mathrm{N} 5$ occurred $>6 \mathrm{~h}$ after the infusions (by which time their effects should have worn off). We first examined the activity of cells in N1-N3 (Fig. 7A). Example firing rate maps from these sessions are shown in Figure $7 B$, with each row depicting a different cell recorded in sessions N1-N3. Also shown are the firing rate maps for the familiar session F3 (before infusion) for these cells. Place fields were observed during the first $10 \mathrm{~min}$ exposure to a novel environment (N1) in all three drug infusion conditions. However, the proportion of cells that exhibited place fields increased significantly across sessions $\mathrm{N} 1-\mathrm{N} 3$ in all three infusion groups (Fig. $7 C$; Pearson's $\chi^{2}=13.793, \mathrm{df}=2, p=0.001$ ). In Figure $7 C$, it also appears that a lower proportion of cells expressed place fields in the CNQX group across the three sessions, but this failed to reach significance (Pearson's $\chi^{2}=3.80, \mathrm{df}=2$, $p=0.15)$. Thus, place fields were expressed in the novel environment under all three drug conditions to a similar extent. Comparison of the firing rate maps for session $\mathrm{F} 3$ and sessions N1-N3 suggest that the cells remapped between the familiar and novel environments in all three drug infusion conditions. To quantify this, we compared the correlations between sessions F3 (just before drug infusion in the familiar environment) and N3 (at which point the novel map should be at its most stable). As can be seen in Figure $7 D$, the mean correlations were close to zero for all three drug conditions, indicating strong remapping between the familiar and novel sessions, with no significant difference among the drug conditions $\left(F_{(2,69)}=0.649, p=0.53\right)$.

Short-term place field stability in a novel environment is decreased following D-AP5 infusions into PoS

To explore the stability of the place fields in the novel environment during the period when the drugs were active, we compared the correlations between sessions N2 and N3 for the three infusion conditions. These sessions were chosen (as opposed to N1 and N2) because (1) fewer cells expressed place fields in N1 than in later sessions in all drug conditions (Fig. 7C), and (2) we observed that, even without drug infusions, place field stability was significantly lower between the first two sessions in a novel environment than between subsequent sessions (Fig. 5D). As can be seen in Figure 7E, following ACSF and CNQX infusions, the 
correlations between $\mathrm{N} 2$ and N3 were similar to those observed between sessions S2 and S3 on Day 1, whereas following D-AP5 infusions the correlations were slightly lower. A one-way ANOVA indicated a significant difference in the $\mathrm{N} 2-\mathrm{N} 3$ correlation among the three drug infusion groups $\left(F_{(2,51)}=3.74, p=0.03\right)$, and post hoc tests (LSD) indicated a significantly lower correlation following AP5 infusions than either ACSF or CNQX infusions $(p<0.05)$. This decreased spatial stability between sessions N2 and N3 following AP5 could not be accounted for by differences in mean firing rates of the place cells, as these did not differ significantly among the three infusion conditions in sessions N1-N3 (session effect, $F_{(2,113)}=0.311, p=0.733$; drug infusion effect, $F_{(2,113)}=0.264, p=0.769$; interaction, $F_{(4,113)}=0.33, p=0.857$; data not shown). Interestingly, spatial information in the cells expressing place fields tended to be higher following CNQX infusions than following AP5 or ACSF infusions. This was confirmed statistically [session effect, $F_{(2,113)}=2.356, p=0.09$; drug effect, $F_{(2,113)}=5.512, p=0.005$; interaction, $F_{(4,113)}=1.674, p=0.161$; post hoc test (Fisher's LSD) on main effect of drug confirmed that CNQX spatial information was significantly greater than D-AP5 and ACSF $p<0.05$; data not shown]. However, this difference cannot account for the lower stability in place field activity between N2 and N3 in the AP5 group compared to the ACSF group, as the spatial information in these conditions did not differ significantly.

Blockade of glutamatergic transmission or plasticity does not disrupt place cell memory $6 \mathrm{~h}$ later

Next, we analyzed the effects of the drug infusions on the long-term stability of place fields in the novel environment by comparing the correlations between N3 (the last session while drugs were active) and N5 ( $>6 \mathrm{~h}$ later, by which time the drugs were no longer active; Fig. $8 A$ ). Five examples of firing rate maps for each condition are shown in Figure $8 B$. As is evident in these examples, infusions of D-AP5 or CNQX had little effect on place

cell stability across a 6 h delay. As seen in Figure $8 C$, there was a trend toward lower correlations between N3 and N5 in the D-AP5 condition, similar to the pattern observed for the N2-N3 correlations. However, there were no significant differences in the N3-N5 correlations between the three drug infusion conditions $\left(F_{(2,54)}=0.861, p=0.428\right)$, indicating that neither CNQX nor D-AP5 significantly affected the ability of cells to form place fields that remained stable over $6 \mathrm{~h}$.

A

B

Cell $203069 \mathrm{t} 1 \mathrm{c} 6$

Cell 314059 t3c5

Cell $427059 \mathrm{t} 3 \mathrm{c} 3$

Cell $525021 \mathrm{t} 4 \mathrm{c} 2$
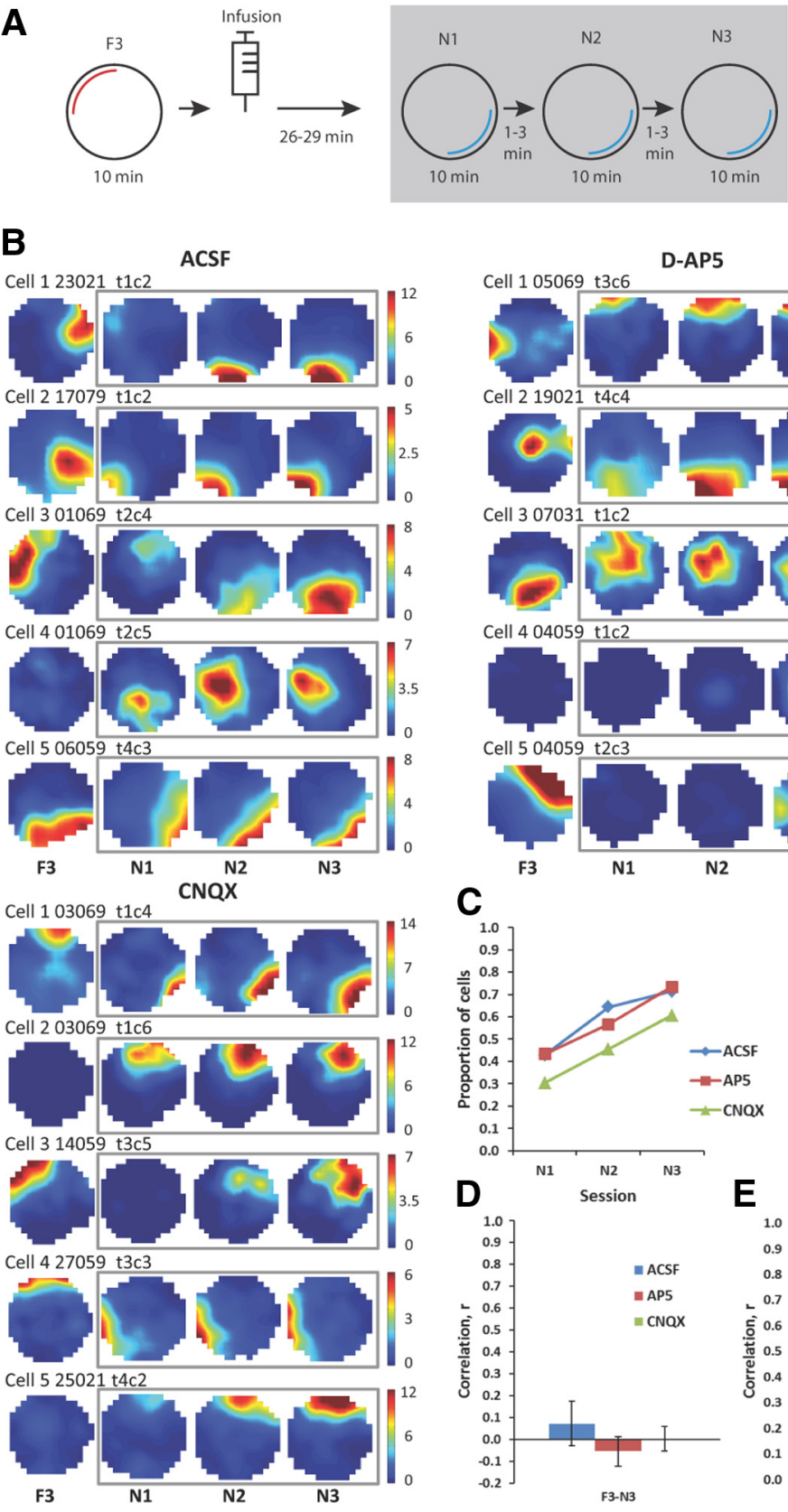

Figure 7. Effects of placement in a novel environment, and infusions of drug or ACSF on place field stability in a novel environment. $\boldsymbol{A}$, Novel environment sequence. $\boldsymbol{B}$, Examples of firing rate maps in the last familiar session before infusion ( $\mathrm{F} 3$ ) and in the novel environment 23-60 min after infusion (N1-N3) into the postsubiculum of ACSF, D-AP5, and CNQX. Boxes around sessions N1-N3 indicate the period when the drug was active. $C$, Across the three initial sessions in the novel environment (N1-N3), the proportion of cells evident increased in all three conditions. There were, however, somewhat fewer place fields observed after infusions of CNQX. D, Place fields remapped between the familiar environment and the novel environment, as evidenced by the lack of correlation in their firing rate maps (F3-N3; N3 was chosen as the proportion of cells in this sessions was higher than the preceding novel sessions $\mathrm{N} 1$ and N2). $\boldsymbol{E}, \mathrm{D}-\mathrm{AP} 5$ decreased the correlation between firing rate maps in the novel environment between sessions N2 and N3, during the period when the drugs were active $\left({ }^{*} p<0.05\right)$. Error bars indicate SEM.

\section{Experiment 3}

The aim of Experiment 3 was to determine whether blocking NMDAR-mediated synaptic plasticity or AMPA/KA-R-mediated synaptic activity in PoS affected the ability to encode the locations of novel objects in a familiar environment. The rationale for this was threefold: First, previous work has shown that combined lesions of PoS and parasubiculum impair object-location recognition memory (Liu et al., 2001), but it is unclear (1) whether this is a result of damage to postsubiculum, parasubiculum, or both, and 
A

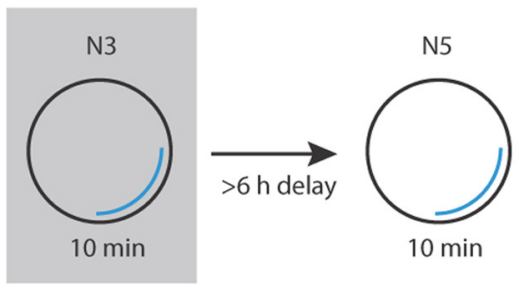

B ACSF

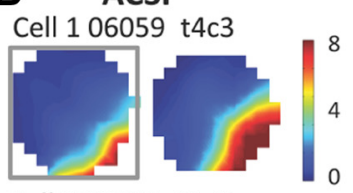

Cell $223021 \mathrm{t} 1 \mathrm{c} 2$

Cell 301069 t2c5

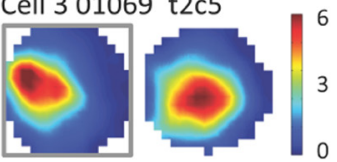

Cell 401069 t3c4

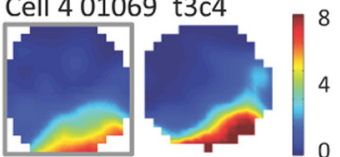

Cell 523021 t3c3

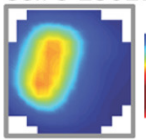

N3

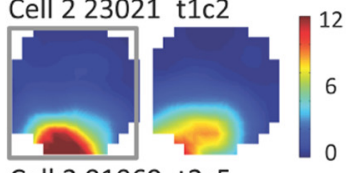

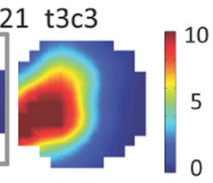

N5
D-AP5

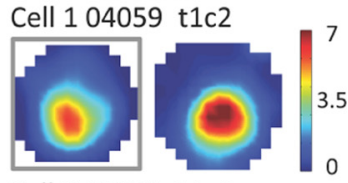

Cell $219021 \mathrm{t} 4 \mathrm{c} 4$

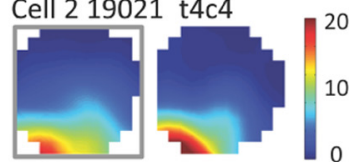

Cell 307031 t1c2

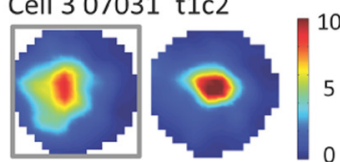

Cell 408059 t3c5

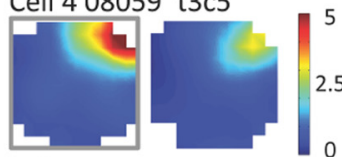

Cell 505069 t4c3

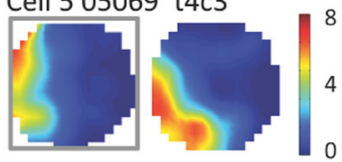

N3

N5
CNQX

Cell 103069 t1c4

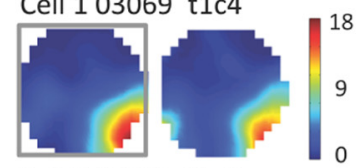

Cell 203069 t1c6

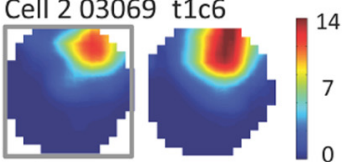

Cell 325021 t4c2

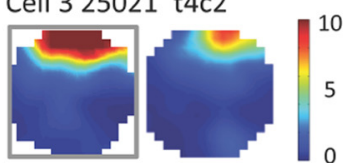

Cell 414059 t3c5
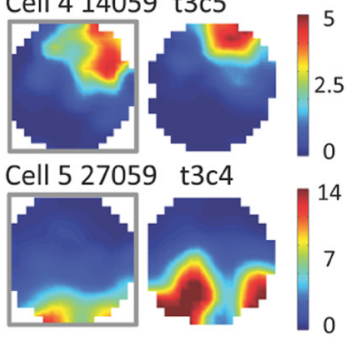

N3

N5

would affect encoding of object-location associations. On one hand, we would expect animals to retrieve a stable place cell representation of a familiar environment during D-AP5. However, it is possible that they would be unable to form new objectlocation associations, if this association requires NMDAR activation in PoS. Rats were tested simultaneously on an object recognition task, to ensure that any deficits in object-location recognition were not due to effects of drug infusions on encoding or memory for objects themselves. We hypothesized that rats would show good object recognition memory under all drug infusion conditions.

\section{Histology}

Nine of the initial 34 rats lost their cannulae implants before completing behavioral testing and were therefore excluded from further analysis. Histological analysis of the brains of the remaining 25 rats revealed that the cannulae tips were accurately located, bilaterally, within the postsubiculum for all but three of the rats. Thus, behavioral analysis was performed on the data from the remaining 22 rats. The cannulae tip placements of these 22 rats are shown in Figure $3 D$.

\section{Infusions of AP5 or CNQX during}

encoding impaired object-location memory but not object memory at $24 \mathrm{~h}$

Data from the three drug infusion days (Days 4, 6, and 8) and the three interleaved noninfusion days (Days 5, 7, and 9) are included in the analysis. The mean durations of exploration of the novel and familiar objects in the memory test phase of the object recognition task across the three drug infusion conditions (ACSF, $\mathrm{D}-\mathrm{AP5}$, and CNQX) and the interleaved noninfusion sessions are shown in Figure $9 A$. Corresponding data depicting the mean duration of exploration of the displaced and stable objects in the objectlocation recognition task are shown in Figure 9B. In the object recognition task, the rats spent more time exploring the novel object than the familiar object in all four conditions (paired $t$ tests two tailed, noninfusion, $t_{(21)}=5.64, p<0.001$; ACSF, $t_{(21)}=5.37, p<0.001 ; \mathrm{D}-\mathrm{AP} 5, t_{(21)}=2.26$, $p<0.05$; CNQX, $\left.t_{(21)}=2.73, p<0.05\right)$. In

(2) whether plasticity or simply activity in PoS is required. Second, having observed a deficit in retrieval of a previously formed representation of a familiar environment following CNQX infusions into PoS, we hypothesized that animals would be impaired in encoding object-location associations in a familiar environment following CNQX infusions, as the place cell representation that would be active as the animals were encoding the objectlocation association during the sample phase of a trial would be unstable. Finally, we were interested in how D-AP5 infusions contrast, in the object-location task rats spent more time exploring the displaced object than the stable object in the noninfusion $\left(t_{(21)}=\right.$ $4.89, p<0.001)$ and ACSF infusion $\left(t_{(21)}=4.27, p<0.01\right)$ conditions, but exploration of the two objects was similar in the D-AP5 $\left(t_{(21)}=1.52, p=0.144\right)$ and $\mathrm{CNQX}\left(t_{(21)}=-1.28, p=0.215\right)$ conditions.

To explore these effects in more detail, and to remove the effects of individual differences in total exploration time, a dis- 
crimination ratio was calculated for each trial (see above, Scoring, inclusion criteria, and data analysis). Mean discrimination ratios for the object recognition and object-location recognition tasks for each condition are shown in Figure 9C and 9D respectively. For the object recognition task, a one-way ANOVA on the discrimination ratios revealed a significant main effect of drug infusion condition $\left(F_{(3,63)}=3.192, p<0.05\right)$. Post hoc pairwise comparisons between the four conditions revealed that performance in the ACSF condition differed significantly from both the CNQX $(p<0.01)$ and noninfusion conditions $(p<0.01)$, but not from the AP5 condition. There were no significant differences between the noninfusion, AP5, and CNQX conditions. This difference among groups appeared to be a result of an increase in discrimination ratio in the ACSF condition, rather than impaired performance in the other conditions. Indeed, one-sample $t$ tests comparing the discrimination ratios to chance (zero) in each condition showed that rats preferentially explored the novel object in all infusion conditions: noninfusion $\left(t_{(21)}=5.66, p<\right.$ $0.001), \operatorname{ACSF}\left(t_{(21)}=8.95, p<0.001\right), \operatorname{AP} 5\left(t_{(21)}=2.82, p<\right.$ $0.01)$, and CNQX $\left(t_{(21)}=2.47, p<0.05\right)$.

A one-way ANOVA on the discrimination ratios for the object-location recognition task also revealed a significant effect of drug infusion condition $\left(F_{(3,63)}=9.937, p<0.001\right)$. Post hoc pairwise comparisons revealed that AP5 and CNQX conditions both differed significantly from the ACSF and noninfusion conditions $(p<0.05)$. The ACSF and noninfusion conditions did not differ significantly from each other, and neither did the AP5 and CNQX conditions. One-sample $t$ tests comparing the discrimination ratios in each drug condition to chance revealed that rats preferentially explored the displaced object in the noninfu$\operatorname{sion}\left(t_{(21)}=4.51, p<0.001\right)$ and $\operatorname{ACSF}\left(t_{(21)}=5.12, p<0.001\right)$ conditions, but not in the AP5 $\left(t_{(21)}=1.11, p=0.28\right)$ and CNQX $\left(t_{(21)}=-1.21, p=0.24\right)$ conditions.

Together, these results indicate a selective impairment in object-location recognition in the rats that received PoS infusions of CNQX or D-AP5 before encoding, while the same infusions left object recognition intact. This finding is consistent with the idea that, although the rats can encode and later retrieve object information, they are unable to encode the locations in which each object appeared during the sample phase if either NMDARs or AMPARs in PoS are blocked.

It is possible that differences in object-location discrimination scores across the infusion conditions could have been an indirect result of differences in object exploration levels during the sample phase (when the drugs would have been active). However, there was no significant difference in total sample phase object exploration between the four conditions for either the object-location recognition task $\left(F_{(3,63)}=1.93, p=0.134\right)$ or the object recognition task $\left(F_{(3,63)}=1.12, p=0.35\right)$, suggesting that the drug infusions did not directly affect object exploration levels (data not shown).

Inspection of the raw times spent exploring the stable and displaced objects during the test phase of the object-location task

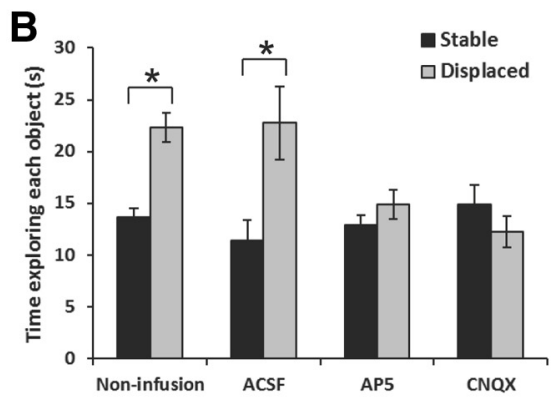

D

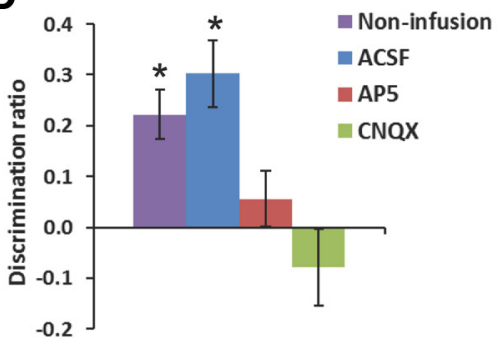


$\mathrm{Hz}$ tetanization can induce LTD in the prefrontal cortex (Otani et al., 1998). We found that LTD was blocked by D-AP5 infused before the tetanus, indicating that our infusions were sufficient to block NMDAR-dependent plasticity in PoS.

Synaptic activity in the postsubiculum, but not NMDARdependent plasticity, is required for stable hippocampal place cell activity in a familiar environment

The finding that blockade of glutamatergic transmission in PoS with CNQX caused hippocampal place cells to remap in a familiar environment is consistent with findings from permanent PoS lesions. Calton et al. (2003) found that in animals with PoS lesions $\sim 40 \%$ of the place cells recorded in a cylindrical environment with a cue card lost their fields during cue-card rotation/ counter-rotation manipulation. The remainder failed to rotate with the cue card when it was shifted by $90^{\circ}$, and there was little correlation between the place field maps in sessions where the cue card remained in the same location.

With the current results, this suggests that place cells require information relayed via PoS to maintain landmark-anchored place fields in familiar environments. The results of Calton et al. (2003) imply that it is not solely head direction cell information that the PoS relays, as lesions of the anterior dorsal thalamus (the likely source of PoS head direction activity) do not yield the same impairments in landmark control of place fields as do PoS lesions. Instead, one possibility is that landmark information is relayed from visual cortical areas directly to the PoS or via the retrosplenial cortex to the PoS (for review, see Yoder et al., 2011). From there, the information may be passed to medial entorhinal cortex (MEC), and then to hippocampus, to mediate landmark anchoring of place fields. The former pathway is supported by the demonstration that the layer of the dorsal PoS that receives input from the retrosplenial cortex in turn projects to the MEC (Kononenko and Witter, 2012). This implies that landmark control of grid and HD cells in MEC in familiar environments should also be disrupted by inactivation of the PoS.

In contrast, D-AP5 infusions had no effect on the activity of place cells in the familiar environment. These data are consistent with the lack of effects of systemic administration of the NMDAR antagonist CPP [(6)-3-(2-carboxypiperazin-4-yl)propyl-1phosphonic acid] on place cell activity in a familiar environment reported previously by Kentros et al. (1998), and confirm that plasticity is not required to express stable place fields in familiar environments.

\section{The postsubiculum is not the site of NMDAR-mediated plasticity mediating place cell "memory" for new environments}

While disruption of NMDAR-mediated plasticity in PoS had a subtle effect on the short-term stability of place fields in a new environment, it did not prevent the formation of a stable place cell representation of a new environment lasting $6 \mathrm{~h}$. Given that systemic infusion of CPP prevents long-term stability of place fields in novel environments (Kentros et al., 1998), these findings suggest that, contrary to our hypothesis, NMDAR-dependent plasticity outside the PoS supports this association.

\section{Synaptic activity in the postsubiculum is not required for stable place cell activity in a novel environment}

Surprisingly, CNQX infusions in PoS did not affect the formation or stability of place fields in the novel environment. This finding contrasts with the remapping seen in the familiar environment following the same infusions. Together, these data suggest that although PoS activity is required for relaying information to support landmark control of hippocampal place fields in a familiar environment, if new associations are being made (as is the case in a novel environment), other structures can support this function.

\section{The postsubiculum is necessary for object-location memory, but not for object recognition}

Both CNQX and D-AP5 infusions impaired encoding of a novel object's location in a familiar environment. Neither treatment blocked object recognition memory, suggesting that the former impairment was related to encoding the location of the objects, and not to encoding the objects themselves.

These results are consistent with effects of combined lesions PoS and adjacent parasubiculum described by Liu et al. (2001). In their study, lesioned animals failed to explore displaced objects more than objects whose position had not changed since a previous exposure. In an object recognition task, the lesioned animals showed preferential exploration of a novel object relative to a familiar object, although the total time spent exploring this object was less than that of the control group. Thus, lesions of PoS and parasubiculum, like temporary inactivation of PoS, impaired the ability to acquire new object-location associations.

The results of Experiment 2 imply the impairments in objectlocation recognition observed following CNQX infusion were the result of failure to activate an appropriate hippocampal representation of the familiar environment. However, this cannot account for the deficits on object-location recognition observed in the D-AP5 condition, as Experiment 2 indicated that blocking NMDARs in PoS did not affect memory for a familiar environment. The current findings suggest that NMDAR-mediated synaptic plasticity in PoS is required for forming new associations between the locations of novel objects and familiar landmarks.

\section{The sites for landmark and object-location learning}

Landmarks differ from objects in that the former are typically stable, polarizing cues that define space, whereas objects may not be fixed or polarizing. Thus landmark and object information may be processed by somewhat different pathways. In landmark learning, a polarizing cue is associated with the animal's internal representation of location and orientation. In the object-location task, the association is between a familiar polarizing landmark and the positions of objects within the environment.

Landmark processing may involve visual projections to the PoS or to the retrosplenial cortex from visual cortex or via the dorsal visual stream (Fig. 1). As PoS and retrosplenial cortex are reciprocally connected and both contain HD cells (Chen et al., 1994), it is possible that they usually both contribute to landmark learning, but that when $\mathrm{PoS}$ is inactivated, retrosplenial cortex is capable of providing sufficient information to the hippocampus for forming new stable place fields. Consistent with this hypothesis, retrosplenial cortex lesions disrupt landmark control of HD cells in anterior dorsal thalamus, although to a lesser extent than PoS lesions (Clark et al., 2010), and retrosplenial inactivation causes place cell instability (Cooper and Mizumori, 2001).

A second possibility is that when PoS is inactivated, the hippocampus relies on alternative pathways to encode novel environments. For example, visual object information processed in the ventral visual stream projects to perirhinal and postrhinal cortices, and from there to entorhinal cortex and hippocampus (for review, see Yoder et al., 2011). Indeed, lesions of perirhinal cortex also result in place cell instability (Muir and Bilkey, 2001). Moreover, there is evidence for the convergence of spatial and object information in these structures: hippocampal place cells 
encode object-location conjunctions (Komorowski et al., 2009; Kim et al., 2011), and neurons in the lateral entorhinal cortex show object-related or object-location firing (Deshmukh and Knierim, 2011), as do neurons in the postrhinal cortex (Furtak et al., 2012). Therefore, to the extent that landmark and object processing overlap (as has been suggested for parahippocampal cortex) (Mullally and Maguire, 2011), plasticity in one or more of these regions may contribute landmark/place field associations. However, there is evidence that the postrhinal cortex is not essential for stable place fields (Nerad et al., 2009).

Object information is likely processed via the ventral visual stream structures outlined above, and this is then combined with the landmark information to support object-location encoding. Our data indicate that this association requires plasticity in PoS. However, the PoS is not the only structure involved in objectlocation memory, as lesions of the hippocampus yield deficits in a similar object-location task (Barker and Warburton, 2011), and plasticity in a network of structures including the hippocampus and perirhinal and prefrontal cortices is required for object-inplace learning (Barker and Warburton, 2008).

\section{Summary}

Previous work has shown that landmark learning requires NMDA receptor-dependent plasticity (Kentros et al., 1998). The current experiments were a first step in specifying the location of this plasticity, and we show that this learning does not occur in the postsubiculum. However, PoS activity is required to maintain place cell stability in a familiar environment. Moreover, both synaptic activity and NMDAR-dependent processes in the postsubiculum are necessary for learning where an object is located within a familiar environment.

\section{References}

Barker GR, Warburton EC (2008) NMDA receptor plasticity in the perirhinal and prefrontal cortices is crucial for the acquisition of long-term object-in-place associative memory. J Neurosci 28:2837-2844. CrossRef Medline

Barker GR, Warburton EC (2011) When is the hippocampus involved in recognition memory? J Neurosci 31:10721-10731. CrossRef Medline

Bast T, da Silva BM, Morris RG (2005) Distinct contributions of hippocampal NMDA and AMPA receptors to encoding and retrieval of one-trial place memory. J Neurosci 25:5845-5856. CrossRef Medline

Bett D, Wood ER, Dudchenko PA (2012) The postsubiculum is necessary for spatial alternation, but not for homing by path integration. Behav Neurosci 126:237-248. CrossRef Medline

Boccara CN, Sargolini F, Thoresen VH, Solstad T, Witter MP, Moser EI, Moser MB (2010) Grid cells in pre- and parasubiculum. Nat Neurosci 13:987-994. CrossRef Medline

Burwell RD (2000) The parahippocampal region: corticocortical connectivity. Ann N Y Acad Sci 91:25-42. Medline

Burwell RD, Witter MP, Amaral DG (1995) Perirhinal and postrhinal cortices of the rat: a review of the neuroanatomical literature and comparison with findings from the monkey brain. Hippocampus 5:390-408. CrossRef Medline

Calton JL, Stackman RW, Goodridge JP, Archey WB, Dudchenko PA, Taube JS (2003) Hippocampal place cell instability after lesions of the head direction cell network. J Neurosci 23:9719-9731. Medline

Clark BJ, Bassett JP, Wang SS, Taube JS (2010) Impaired head direction cell representation in the anterodorsal thalamus after lesions of the retrosplenial cortex. J Neurosci 14:5289-5302. CrossRef Medline

Cooper BG, Mizumori SJ (2001) Temporary inactivation of the retrosplenial cortex causes a transient reorganization of spatial coding in the hippocampus. J Neurosci 21:3986-4001. Medline

Deshmukh SS, Knierim JJ (2011) Representation of non-spatial and spatial information in the lateral entorhinal cortex. Frontiers Behav Neurosci 5:69. Medline

Dudchenko PA (2010) Why people get lost: the psychology and neuroscience of spatial cognition. Oxford, UK: Oxford UP.
Dudek SM, Bear MF (1992) Homosynaptic long-term depression in area CA1 of hippocampus and effects of $\mathrm{N}$-methyl-D-aspartate receptor blockade. Proc Natl Acad Sci U S A 89:4363-4367. CrossRef Medline

Frank LM, Stanley GB, Brown EN (2004) Hippocampal plasticity across multiple days of exposure to novel environments. J Neurosci 24: 7681-7689. CrossRef Medline

Furtak SC, Ahmed OJ, Burwell RD (2012) Single neuron activity and theta modulation in postrhinal cortex during visual object discrimination. Neuron 76:976-988. CrossRef Medline

Golob EJ, Taube JS (1997) Head direction cells and episodic spatial information in rats without a hippocampus. Proc Natl Acad Sci U S A 94:76457650. CrossRef Medline

Golob EJ, Taube JS (1999). Head direction cells in rats with hippocampal or overlying neocortical lesions: evidence for impaired angular path integration. J Neurosci 19:7198-7211. Medline

Goodridge JP, Taube JS (1997) Interaction between the postsubiculum and anterior thalamus in the generation of head direction cell activity. J Neurosci 17:9315-9330. Medline

Goodridge JP, Dudchenko PA, Worboys KA, Golob EJ, Taube JS (1998) Cue control and head direction cells. Behav Neurosci 112:749-761.

Hafting T, Fyhn M, Molden S, Moser MB, Moser EI (2005) Microstructure of a spatial map in the entorhinal cortex. Nature 436:801-806. CrossRef Medline

Hedberg TG, Stanton PK (1995) Long-term potentiation and depression of synaptic transmission in rat posterior cingulate cortex. Brain Res 670: 181-196. CrossRef Medline

Huang YS (2010) Exploring how spatial learning can affect the firing of place cells and head direction cells: the influence of changes in landmark configuration and the development of goal-directed spatial behaviour. $\mathrm{PhD}$ thesis, School of Informatics, University of Edinburgh.

Ikegaya Y, Saito H, Abe K (1994) Attenuated hippocampal long-term potentiation in basolateral amygdala-lesioned rats. Brain Res 656:157-164. CrossRef Medline

Kentros C, Hargreaves E, Hawkins RD, Kandel ER, Shapiro M, Muller RV (1998) Abolition of long-term stability of new hippocampal place cell maps by NMDA receptor blockade. Science 280:2121-2126. CrossRef Medline

Kesner RP, Giles R (1998) Neural circuit analysis of spatial working memory: role of pre- and parasubiculum, medial and lateral entorhinal cortex. Hippocampus 8:416-423. CrossRef Medline

Kim J, Delcasso S, Lee I (2011) Neural correlates of object-in-place learning in hippocampus and prefrontal cortex. J Neurosci 31:16991-17006. CrossRef Medline

Komorowski RW, Manns JR, Eichenbaum H (2009) Robust conjunctive item-place coding by hippocampal neurons parallels what happens where. J Neurosci 29:9918-9929. CrossRef Medline

Kononenko NL, Witter MP (2012) Presubiculum layer III conveys retrosplenial input to the medial entorhinal cortex. Hippocampus 22:881-895. CrossRef Medline

Kubie JL (1984) A driveable bundle of microwires for collecting single-unit data from freely-moving rats. Physiol Behav 32:115-118. CrossRef Medline

Leutgeb JK, Leutgeb S, Moser MB, Moser EI (2007) Distinct mechanisms for pattern separation in dentate gyrus and CA3 of the hippocampal formation. Science 315:961-966. CrossRef Medline

Liu P, Jarrard LE, Bilkey DK (2001) Excitotoxic lesions of the pre- and parasubiculum disrupt object recognition and spatial memory processes. Behav Neurosci 115:112-124. CrossRef Medline

Liu P, Jarrard LE, Bilkey DK (2004) Excitotoxic lesions of the pre- and parasubiculum disrupt the place fields of hippocampal pyramidal cells. Hippocampus 14:107-116. CrossRef Medline

Markus EJ, Barnes CA, McNaughton BL, Gladden VL, Skaggs WE (1994) Spatial information content and reliability of hippocampal CA1 neurons: effects of visual input. Hippocampus 4:410-421. Medline

Muir GM, Bilkey DK (2001) Instability in the place field location of hippocampal place cells after lesions centered on the perirhinal cortex. J Neurosci 21:4016-4025. Medline

Mullally SL, Maguire EA (2011) A new role for parahippocampal cortex in representing space. J Neurosci 31:7441-7449. CrossRef Medline

Muller RU, Kubie JL (1987) The effects of changes in the environment on the spatial firing of hippocampal complex-spike cells. J Neurosci 7:19511968. Medline 
Nerad L, Liu P, Bilkey DK (2009) Bilateral NMDA lesions centered on the postrhinal cortex have minimal effects on hippocampal place cell firing. Hippocampus 19:221-227. CrossRef Medline

O'Keefe J, Conway DH (1978) Hippocampal place units in the freely moving rat: why they fire where they fire. Exp Brain Res 31:573-590. Medline

Otani S, Blond O, Desce JM, Crépel F (1998) Dopamine facilitates longterm depression of glutamatergic transmission in rat prefrontal cortex. Neuroscience 85:669-676. CrossRef Medline

Robinson S, Bucci DJ (2012) Fear conditioning is disrupted by damage to the postsubiculum. Hippocampus 22:1481-1491. CrossRef Medline

Rowland DC, Yanovich Y, Kentros CG (2011) A stable hippocampal representation of a space requires its direct experience. Proc Natl Acad Sci U S A 108:14654-14658. CrossRef Medline

Shires KL, Hawthorne JP, Hope AMJ, Dudchenko PA, Wood ER, Martin SJ (2013) Functional connectivity between the thalamus and postsubiculum: analysis of evoked responses elicited by stimulation of the laterodorsal thalamic nucleus in anesthetized rats. Hippocampus. Advance online publication. Retrieved Feb. 16, 2013. doi:10.1002/ hipo.22114. CrossRef Medline

Suzuki S, Augerinos G, Black AH (1980) Stimulus control of spatial behavior on the eight-arm maze in rats. Learning Motivation 11:1-18. CrossRef
Taube JS (1995) Head direction cells recorded in the anterior thalamic nuclei of freely moving rats. J Neurosci 15:70-86. Medline

Taube JS, Muller RU, Ranck JB Jr (1990a) Head-direction cells recorded from the postsubiculum in freely moving rats. I. Description and quantitative analysis. J Neurosci 10:420-435. Medline

Taube JS, Muller RU, Ranck JB Jr (1990b) Head-direction cells recorded from the postsubiculum in freely moving rats. II. Effects of environmental manipulations. J Neurosci 10:436-447. Medline

Taube JS, Kesslak JP, Cotman CW (1992) Lesions of the rat postsubiculum impair performance on spatial tasks. Behav Neural Biol 57:131-143. CrossRef Medline

van Groen T, Wyss JM (1992) Projections from the laterodorsal nucleus of the thalamus to the limbic and visual cortices in the rat. J Comp Neurol 324:427-448. Medline

Witter MP, Amaral DG (2004) Hippocampal formation. In: The rat nervous system, Ed 3 (Paxinos G, ed), pp 635-704. San Diego: Elsevier Academic.

Wolbers T, Hegarty M (2010) What determines our navigational abilities? Trends Cogn Sci 14:138-146. CrossRef Medline

Yoder RM, Clark BJ, Taube JS (2011) Origins of landmark encoding in the brain. Trends Neurosci 34:561-571. CrossRef Medline 